\title{
Coordination Compounds of Niobium(IV) Oxide Dihalides Including the Synthesis and the Crystallographic Characterization of NHC Complexes
}

Marco Bortoluzzi, ${ }^{a}$ Eleonora Ferretti, ${ }^{b, \S}$ Fabio Marchetti, ${ }^{b,{ }^{*}}$ Guido Pampaloni, ${ }^{b}$ Calogero Pinzino, ${ }^{c}$ Stefano Zacchini ${ }^{d}$

${ }^{a}$ Dipartimento di Scienze Molecolari e Nanosistemi, Università di Venezia Ca' Foscari, Via Torino 155, I-30170 Mestre (Venezia).

${ }^{b}$ Dipartimento di Chimica e Chimica Industriale, Università di Pisa, Via G. Moruzzi 13, I-56124 Pisa, Italy.

${ }^{c}$ ICCOM-CNR UOS Pisa, Research Area, Via Moruzzi 1, I-56124 Pisa, Italy.

'Dipartimento di Chimica Industriale “Toso Montanari”, Università di Bologna, Viale Risorgimento 4, I-40136 Bologna, Italy.

$\S$ Present address: Institut für Anorganische Chemie, Georg-August-Universität Göttingen, Tammannstrasse 4, D-37077 Göttingen, Germany. 


\begin{abstract}
The 1:1 molar reactions of $\mathrm{NbOX}_{3}$ with $\mathrm{SnBu}_{3} \mathrm{H}$, in toluene at $0{ }^{\circ} \mathrm{C}$ in the presence of oxygen/nitrogen donors, resulted in the formation of $\mathrm{NbOX}_{2} \mathrm{~L}_{2}\left(\mathrm{X}=\mathrm{Cl}, \mathrm{L}_{2}=\mathrm{dme}, \mathbf{2} \mathbf{a} ; \mathrm{X}=\mathrm{Br}, \mathrm{L}_{2}=\mathrm{dme}, \mathbf{2} \mathbf{b} ; \mathrm{X}=\mathrm{Cl}, \mathrm{L}=\right.$ thf, 2c; $\mathrm{X}=\mathrm{Cl}, \mathrm{L}=\mathrm{NCMe}, \mathbf{2 d}$; dme = 1,2-dimethoxyethane, thf = tetrahydrofuran), in good yields. The 1:2 reactions of freshly prepared $\mathbf{2 d}$ and $\mathbf{2 b}$ with the bulky NHC ligands 1,3-bis(2,4,6-trimethylphenyl)imidazol-2-ylidene, Imes, and 1,3-bis(2,6-dimethyl-phenyl)imidazol-2-ylidene, Ixyl, respectively, afforded the complexes $\mathrm{NbOCl}_{2}(\operatorname{Imes})_{2}, \mathbf{3}$, and $\mathrm{NbOBr}_{2}(\operatorname{Ixyl})_{2}, \mathbf{4}$, in $50-60 \%$ yields. The reactions of $\mathbf{2 b}$ with $\mathrm{NaOR}$, in tetrahydrofuran, gave $\mathrm{NbOCl}(\mathrm{OR})(\mathrm{R}=\mathrm{Ph}, 5 ; \mathrm{R}=\mathrm{Me}, \mathbf{6})$ in about $60 \%$ yields. All the products were characterized by analytical and spectroscopic techniques, moreover DFT calculations were carried out in order to shed light on synthetic and structural features. Compounds $\mathbf{3}$ and $\mathbf{4}$, whose molecular structures have been ascertained by X-ray diffraction, represent very rare example of crystallographically characterized niobium-NHC systems.
\end{abstract}

\title{
Introduction
}

Since Arduengo's isolation of the first crystalline N-heterocyclic carbene (NHC) in 1991, the use of NHC ligands in organometallic chemistry has seen a tremendous advance, with applications ranging from medicinal chemistry to homogeneous catalysis and material science. ${ }^{1}$ The chemistry of NHC ligands has been developed especially with reference to low and medium valent metals, belonging to middle to late transition groups. Otherwise NHC systems based on oxophilic, early transition metals have been much less investigated, and one of the reasons may be attributed to the possible moisture sensitivity affecting the reaction systems. ${ }^{2}$ In particular, niobium represents a surprising exception in the crowded scenario of the NHC chemistry: ${ }^{3}$ indeed very few Nb-NHC systems have appeared in the 
literature so far, 3,4 and we have recently contributed with the unique structurally characterized niobium complex containing a monodentate NHC ligand. ${ }^{3}$

Niobium pentahalides are among the most easily available and cost effective niobium species: their chemistry has undergone a significant progress in the last decade, encouraged by the low toxicity associated with the metal element and the outstanding reactivity patterns observed in some $\mathrm{NbX}_{5^{-}}$ directed organic transformations. ${ }^{5}$ Niobium(V) pentahalides have been employed as convenient starting reagents to access both $\mathrm{Nb}(\mathrm{IV})$ and $\mathrm{Nb}(\mathrm{III})$ halides, ${ }^{6}$ which in turn have found applications in synthetic organic chemistry. ${ }^{5 b, 7}$ Also niobium (V) oxide trichlorides and tribromides are rather easily accessible compounds, ${ }^{8}$ whose coordination chemistry has been investigated to some extent. ${ }^{9}$ On the other hand, the synthesis of reduced niobium oxide halides, that are materials of potential interest also in view of their solid state properties, ${ }^{10}$ is a more difficult task. More in detail, the reported synthetic procedures to afford $\mathrm{NbOX}_{2}(\mathrm{X}=\mathrm{Cl}, \mathrm{Br})$ require prohibitive experimental conditions, ${ }^{11}$ thus determining an important drawback to the acquisition of the knowledge of the reactivity of these compounds. As a matter of fact, the coordination chemistry of $\mathrm{NbOX}_{2}(\mathrm{X}=\mathrm{Cl}, \mathrm{Br})$ has been almost unexplored heretofore: the only coordination adducts were claimed to be prepared by hydrolysis of niobium tetrachloride compounds ${ }^{12}$ or reduction of $\mathrm{NbOCl}_{3} /$ phosphine systems with $\mathrm{Na} / \mathrm{Hg}$, however the products were not unambiguously characterized. $^{12 \mathrm{a}}$

Herein we present a convenient room temperature procedure to afford complexes of $\mathrm{NbOCl}_{2}$ and $\mathrm{NbOBr}_{2}$ with simple oxygen and nitrogen donor ligands, starting from the corresponding niobium pentahalides. These $\mathrm{Nb}(\mathrm{IV})$ products undergo substitution reactions with phenoxide and methoxide anions and with bulky, monodentate NHC ligands (Chart 1), affording fairly air stable $\mathrm{NbOX}_{2}\left(\mathrm{NHC}_{2}\right.$ complexes. The synthetic aspects and the structural characterization of the new complexes (including Xray characterization of the NHC complexes) will be discussed, with the assistance of DFT results. 


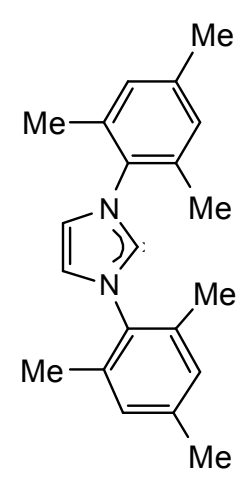

Imes

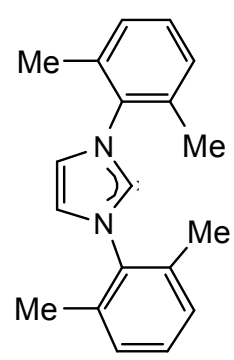

Ixyl

Chart 1. NHC ligands used in the present work.

\section{Results and discussion}

We prepared $\mathrm{NbOX}_{3}(\mathrm{X}=\mathrm{Cl}, \mathrm{Br})$ in $c a .80 \%$ yields by allowing the respective precursors $\mathrm{NbX}_{5}$ to react with one equivalent of hexamethyldisiloxane, in dichloromethane at room temperature, Eqn. 1. This method was previously reported for $\mathrm{NbOCl}_{3},{ }^{8 \mathrm{c}}$ and has been employed here also to obtain $\mathrm{NbOBr}_{3}{ }^{13}$

$$
\begin{gathered}
\mathrm{NbX}_{5}+\mathrm{O}\left(\mathrm{SiMe}_{3}\right)_{2} \rightarrow \mathrm{NbOX} \\
\mathrm{X}=\mathrm{Cl}, \mathrm{Br}
\end{gathered}
$$

The complexes $\mathrm{NbOX}_{3}(\mathrm{dme})\left(\mathrm{X}=\mathrm{Cl},{ }^{14} \mathrm{Br}\right.$; dme $=1$,2-dimethoxyethane), 1a-b, were afforded in good yields upon addition of dme to $\mathrm{NbOX}_{3}$ in toluene, Eqn. 2.

$$
\begin{gathered}
\mathrm{NbOX}_{3}+\mathrm{dme} \rightarrow \mathrm{NbOX}_{3}(\mathrm{dme}) \\
\mathrm{X}=\mathrm{Cl}, \mathbf{1 a} \\
\mathrm{X}=\mathrm{Br}, \mathbf{1 b}
\end{gathered}
$$

According to NMR evidences, the unprecedented $\mathbf{1 b}$ exists in dichloromethane solution as a single isomeric form $\left({ }^{93} \mathrm{Nb}\right.$ resonance at $\left.-205 \mathrm{ppm}\right)$, presumably ascribable to a (distorted) octahedral geometry with mer configuration $\left({ }^{13} \mathrm{C}\right.$ NMR resonances due to the non equivalent methyl groups occur at 70.3 and $63.6 \mathrm{ppm})$. This result is consistent with DFT EDF2 calculations, the mer isomer resulting more stable than the $f a c$ one by about $8.9 \mathrm{kcal} \mathrm{mol}^{-1}$ (Gibbs free energy). Figure S1 and Table S1 within the SI show 
the calculated structures of the possible isomers of $\mathbf{1 b}$, and the bonding parameters related to the most stable isomer.

It should be remarked that niobium chlorides and bromides bearing niobium in a reduced oxidation state can be afforded by the straightforward reactions of $\mathrm{NbX}_{5}$ with the appropriate amount of $\mathrm{Sn}^{n} \mathrm{Bu}_{3} \mathrm{H}^{6}{ }^{6}$ For instance, $\mathrm{NbX}_{3}(\mathrm{dme})$ can be generated in high yields from $\mathrm{NbX}_{5}$ and two equivalents of $\mathrm{Sn}^{n} \mathrm{Bu}_{3} \mathrm{H}$ in dme. Therefore, with the aim of obtaining niobium(IV) oxide dihalides, we studied the possible reduction process of $\mathbf{1} \mathbf{a}, \mathbf{b}$ with tributyltin hydride. These reactions successfully led to the formation of $\mathrm{NbOX}_{2}(\mathrm{dme})(\mathrm{X}=\mathrm{Cl}, \mathbf{2 a} ; \mathrm{Br}, \mathbf{2 b})$. Optimal reaction conditions imply the addition of tributyltin hydride to toluene solutions of in situ generated 1a-b (Scheme 1). By using this method, 2a,b were isolated after work up in $60-65 \%$ yields as dark blue/violet solids. Following analogous procedures, also the complexes $\mathrm{NbOCl}_{2}(\text { thf })_{2}, \mathbf{2 c}$, and $\mathrm{NbOCl}_{2}(\mathrm{NCMe})_{2}, \mathbf{2 d}$, were obtained (Scheme 1).

2c-d are exceedingly air sensitive products, and especially $\mathbf{2 d}$ is so intractable that a satisfying characterization has not been possible. Attempts to prepare acetonitrile and tetrahydrofuran adducts of $\mathrm{NbOBr}_{2}$ did fail.

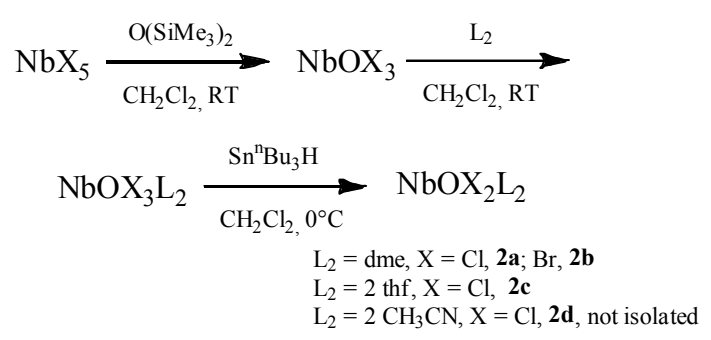

Scheme 1. Synthesis of $\mathrm{NbOX}_{2} \mathrm{~L}_{2}$ complexes

Compounds 2a-c represent rare examples of well defined coordination complexes of $\mathrm{NbOX}_{2}$. They were characterized by elemental and magnetic analysis, IR and UV-Vis spectroscopy. The magnetic susceptivity values of $\mathbf{2} \mathbf{a}-\mathbf{b}$ are lower than the spin only value (1.73 BM) for a $\mathrm{d}^{1}$-species, and fall in within the interval 1.40-1.65 $\mathrm{BM}$, resembling previous findings on mono and dinuclear $\mathrm{Nb}(\mathrm{IV})$ 
complexes. ${ }^{15}$ The IR spectra of $\mathbf{2 a - b}$ display a strong band at $c a .1020 \mathrm{~cm}^{-1}$, attributed to terminal $\mathrm{Nb}=\mathrm{O}$ moiety. In the UV-Vis spectra, absorptions in the region $450-750 \mathrm{~nm}$ are featured by low molar extinction coefficients and are probably due to d-d transitions within the metal ion.

According to the experimental evidences, we suggest that $\mathbf{2 a - b}$ hold a dinuclear structure similar to that adopted by $\mathrm{NbX}_{5}{ }^{16}$ and $\mathrm{MoCl}_{5}{ }^{17}$ in the solid state, with the hexacoordinated metal centers sharing two bridging halide ligands. It should be noted that the $\mathrm{d}^{1}$ metal based dimeric $\mathrm{MoCl}_{5}$ displays a magnetic susceptivity corresponding to a magnetic moment of $1.6 \mathrm{BM} .{ }^{18}$ Furthermore, the only two examples of crystallographically characterized vanadium(IV) complexes based on the core $\mathrm{VOCl}_{2} \mathrm{~L}_{2}$ and containing terminal oxide ligands, i.e. $\mathrm{VOCl}_{2}(\mathrm{NCMe})_{2}$ and $\left[\mathrm{VOCl}_{3}\left(\mathrm{OH}_{2}\right)\right]^{-}$, possess a dinuclear structure. ${ }^{19}$

On theoretical grounds, among the possible dinuclear structures of 2a (Figure S2, Table S2), that one containing two bridging chlorines and the oxide ligands in axial positions (2aA) resulted to be the slightly most stable one (EDF2 calculations). Instead 2aA is largely more stable compared to the corresponding monomeric form. ${ }^{20}$ Similar conclusions were achieved by DFT analysis (EDF2 level) on 2b (Figure S3, Table S3). ${ }^{20}$ The geometry of the most stable form of $\mathbf{2 b}$, i.e. $\mathbf{2 b}$ A (Figure S3), was optimized also by using the $\omega$ B97X DFT functional in combination with a polarized split-valence basis set and the C-PCM salvation model for dichloromethane: the result is drawn in Figure 1, with the caption reporting selected bonding parameters.

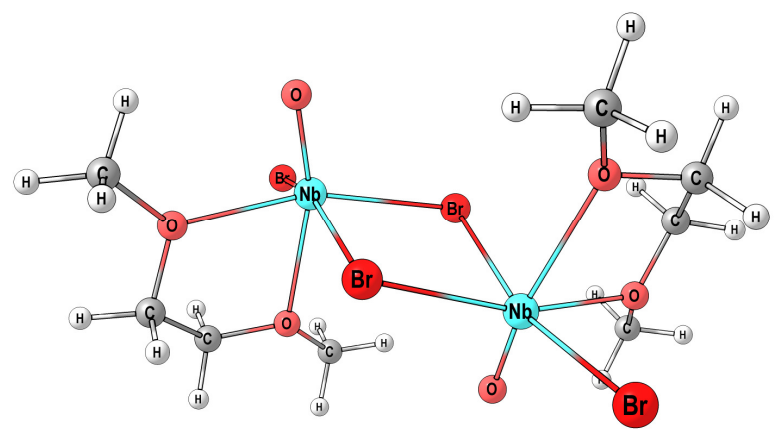

Figure 1. DFT-optimized structure of $\mathbf{2 b A}(\mathrm{C}-\mathrm{PCM} / \omega \mathrm{B} 97 \mathrm{X}$,

dichloromethane as implicit solvent). Selected bond lengths $(\AA)$ :

$\mathrm{Nb}=\mathrm{O}$ 1.681, 1.682; $\mathrm{Nb}-\mathrm{O} \quad 2.275, \quad 2.436,2.277, \quad 2.431$; 
$\mathrm{Nb}-\mathrm{Br}$ (terminal) 2.633, 2.631; $\mathrm{Nb}-\mathrm{Br}$ (bridging) 2.726, 2.793, 2.718,

2.783; $\mathrm{Nb}---\mathrm{Nb}$ 4.045. Selected angles $\left({ }^{\circ}\right): \mathrm{O}=\mathrm{Nb}-\mathrm{O}$ 91.4, 160.4,

92.3, 161.0; $\mathrm{O}-\mathrm{Nb}-\mathrm{O}$ 69.5, 69.3; $\mathrm{O}=\mathrm{Nb}-\mathrm{Br}$ (terminal) 102.3, 103.1;

$\mathrm{O}=\mathrm{Nb}-\mathrm{Br}$ (bridging) $\quad 95.9, \quad 106.3, \quad 95.1, \quad 103.1$;

Br(bridging) $-\mathrm{Nb}-\mathrm{Br}$ (bridging) 84.6, 84.9.

Even though it was not possible to isolate and characterize the acetonitrile adduct $\mathbf{2 d}$, we studied by

DFT the possible dinuclear structures for this compound. The computer outcomes matched the results achieved for 2a-b. Thus EDF2 calculations indicated $\mathbf{2 d C}$, containing bridging $\mathrm{Cl}$-ligands, as the most

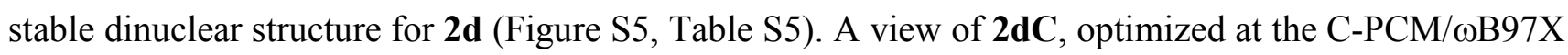
DFT level, is provided as Figure 2.

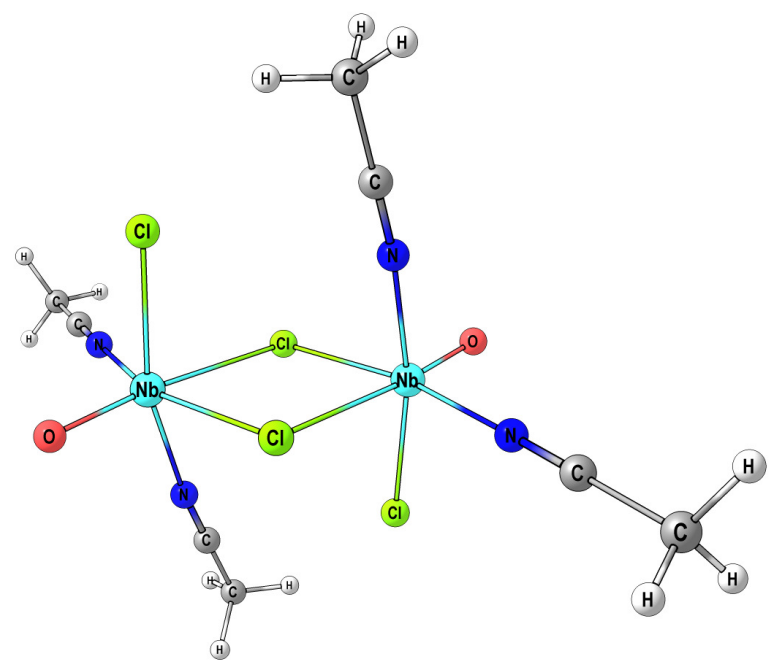

Figure 2. DFT-optimized structure of 2dC (C-PCM/ $/ \mathrm{B} 97 \mathrm{X}$, dichloromethane as implicit solvent). Selected bond lengths $(\AA)$ : $\mathrm{Nb}=\mathrm{O} \quad 1.681, \quad 1.681 ; \quad \mathrm{Nb}-\mathrm{N} \quad 2.235, \quad 2.249, \quad 2.235, \quad 2.249$; $\mathrm{Nb}-\mathrm{Cl}$ (terminal) 2.476, 2.477; $\mathrm{Nb}-\mathrm{Cl}$ (bridging) 2.535, 2.945, 2.535, 2.956; $\mathrm{Nb}---\mathrm{Nb} 4.202$. Selected angles $\left(^{\circ}\right)$ : $\mathrm{O}=\mathrm{Nb}-\mathrm{N}$ 95.1, 97.6, 95.1, 97.6; $\mathrm{O}-\mathrm{Nb}-\mathrm{Cl}$ (terminal) 103.1, 103.1; $\mathrm{O}=\mathrm{Nb}-\mathrm{Cl}$ (bridging) 103.5, 169.7, 103.5, 169.7; $\mathrm{Cl}$ (bridging)- $\mathrm{Nb}-\mathrm{Cl}$ (bridging) 80.2, 80.2.

In contrast with the computational findings related to $\mathbf{2 a}, \mathbf{b}, \mathbf{d}$, major stability of $\mu$-O containing structures is predictable for the tetrahydrofuran adduct $\mathbf{2 c}$. The calculated dinuclear structures of $\mathbf{2 c}$ are shown in Figure S4, and a view of the lowest energy structure (2cE) is given also as Figure 3. The computer outcome on $\mathbf{2 c}$ is consistent with the experimental data. Indeed, no intense IR absorption was detected in 
the $1010-1030 \mathrm{~cm}^{-1}$ region (terminal $\mathrm{Nb}=\mathrm{O}$, see above); otherwise a band at $672 \mathrm{~cm}^{-1}$ was attributed to vibration of the $\mathrm{Nb}-\mathrm{O}-\mathrm{Nb}$ moieties. In addition, the magnetic measurement on $\mathbf{2 c}$ furnished a lower value $(1.19 \mathrm{BM})$ than what expected for isolated $\mathrm{Nb}(\mathrm{IV})$ centers, in agreement with the presence of bridging oxide groups allowing some communication between the niobium centers.

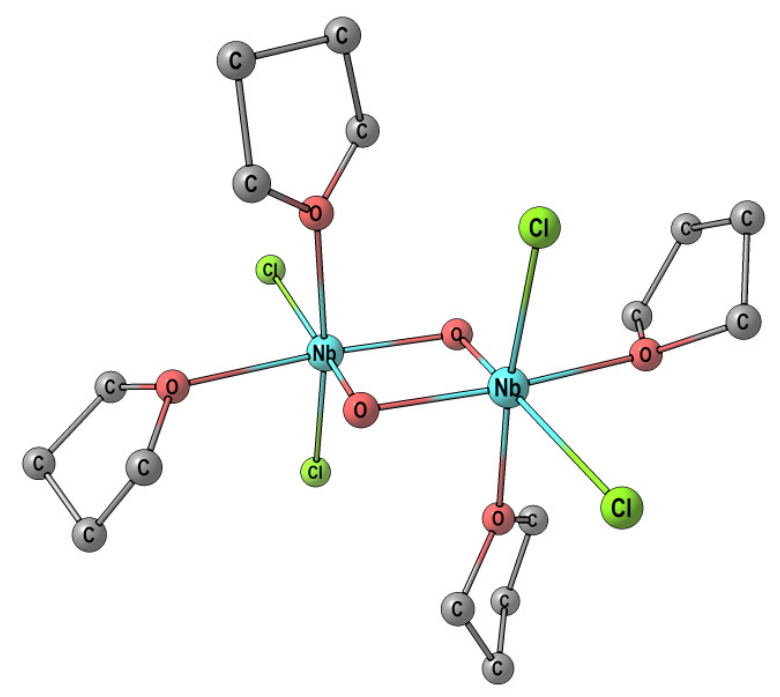

Figure 3. Lowest energy DFT EDF2 calculated structure of $2 \mathbf{c}(\mathbf{2 c E}$, see Figure S4). Selected bond lengths $(\AA) \mathrm{Nb}-\mathrm{Cl}$ (trans thf) 2.434; $\mathrm{Nb}-\mathrm{Cl}($ trans $\mu-\mathrm{O}) \quad 2.450,2.452 ; \mathrm{Nb}-\mathrm{O}$ (thf, trans $\mathrm{Cl}) 2.239$, 2.248; $\mathrm{Nb}-\mathrm{O}$ (thf, trans $\mu-\mathrm{O}) 2.331,2.329 ; \mathrm{Nb}-\mathrm{O}(\mu) \quad 1.894,2.030$, 1.892, 2.021 Selected angles $\left({ }^{\circ}\right)$ : $\mathrm{Cl}-\mathrm{Nb}-\mathrm{Cl} 91.2,90.8 ; \mathrm{O}($ thf $)-\mathrm{Nb}-$ $\mathrm{O}$ (thf) $88.7,89.1 ; \mathrm{O}(\mu)-\mathrm{Nb}-\mathrm{O}(\mu) 79.5,79.8$.

2a-d are highly air sensitive compounds (see above), their decomposition being completed within a few seconds if allowed to contact with air. On account of the fact that simple mononuclear coordination adducts of $\mathrm{NbCl}_{5}$ with bulky NHC ligands have exhibited superior resistance to hydrolysis, respect to the precursor $\mathrm{NbCl}_{5}$, we reckoned that the introduction of a bulky NHC ligand could significantly improve the air inertness of the $\mathrm{Nb}(\mathrm{IV})$ compounds. The NHC molecules 1,3-bis(2,4,6-trimethylphenyl)imidazol-2-ylidene, Imes, and 1,3-bis(2,6-dimethyl -phenyl)imidazol-2-ylidene, Ixyl, were selected to the present study (Chart 1). 
According to DFT, the substitution reactions of the organic ligands in 2a-d with NHC units appear energetically favorable (see for instance Eqns. 3 and 4).

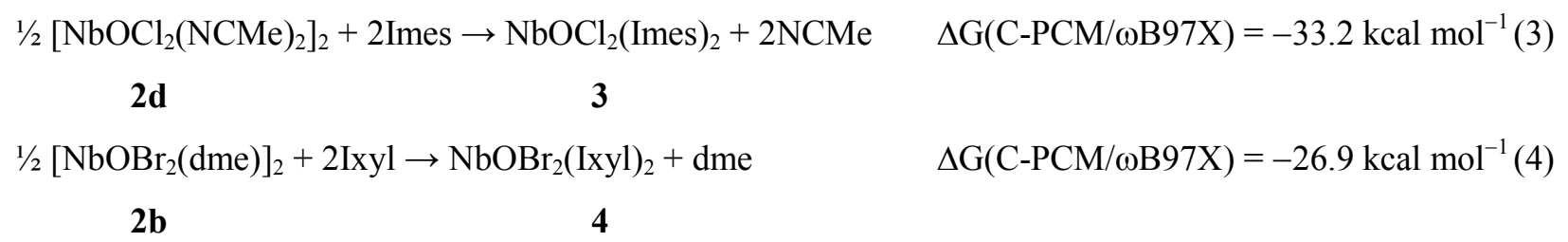

The NHC complex $\mathbf{4}$ could be actually afforded from $\mathbf{2 b} /$ Ixyl, while freshly prepared $\mathbf{2 d}$ revealed to be the preferential starting material (rather than $\mathbf{2 a}$ and $\mathbf{2 c}$ ) for the synthesis of $\mathbf{3}$. These reactions were performed in toluene at ca. $50{ }^{\circ} \mathrm{C}$, then $\mathbf{3}$ and $\mathbf{4}$ were isolated as brown solids in 50-60\% yields (Scheme 2).

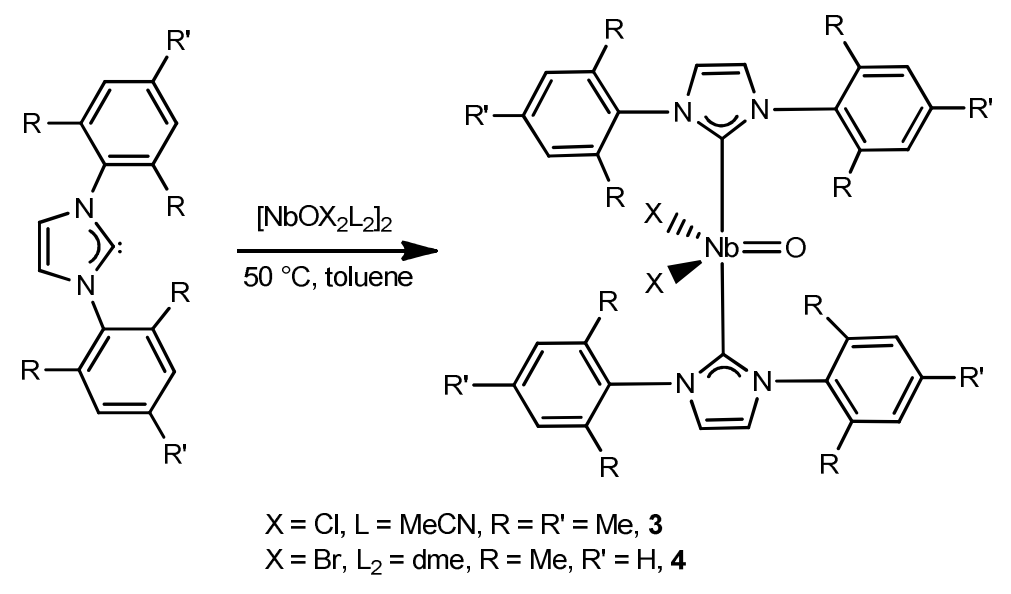

Scheme 2. Preparation of niobium(IV) NHC complexes.

Compounds 3 and $\mathbf{4}$ are fairly air stable (decomposition completed within 5-15 minutes). The IR spectra (in the solid state) contain the absorption related to the $\mathrm{Nb}=\mathrm{O}$ moiety at $1035 \mathrm{~cm}^{-1}$. Magnetic susceptibilities were as expected for mononuclear $\mathrm{Nb}(\mathrm{IV})$ complexes, ${ }^{15}$ and comparable to the value reported for $\mathrm{VOCl}_{2}(\mathrm{Imes})_{2}{ }^{2 \mathrm{~d}}$ In the UV-Vis spectra, the absorptions in the region $300-400 \mathrm{~nm}$ are 
ascribable to the NHC ligands. Crystals of both $\mathbf{3}$ and $\mathbf{4}$ suitable for X-ray diffraction could be collected after several attempts. The molecular structures of $\mathbf{3}$ and $\mathbf{4}$ are shown, respectively, in Figures 4 and 5 , with relevant bonding parameters reported in Table 1.3 and $\mathbf{4}$ represent the first examples of structurally characterized $\mathrm{Nb}(\mathrm{IV})$ complexes of the type $\mathrm{NbOX}_{2} \mathrm{~L}_{2}(\mathrm{X}=$ anionic ligand; $\mathrm{L}=$ neutral ligand $)$. From the other side, they are isostructural with $\mathrm{VOCl}_{2}(\mathrm{IMes})_{2}$, ${ }^{2 \mathrm{~d}}$ thus displaying a distorted trigonal bipyramidal structure with the oxido and the halide ligands in equatorial positions, whereas the two NHC ligands occupy the two axial positions. The probable cleavage of the dinuclear structure of $\mathbf{2 d}$ and $\mathbf{2 b}$ (see above), upon addition of two NHCs, seems to be consequence of the encumbrance of the latter.

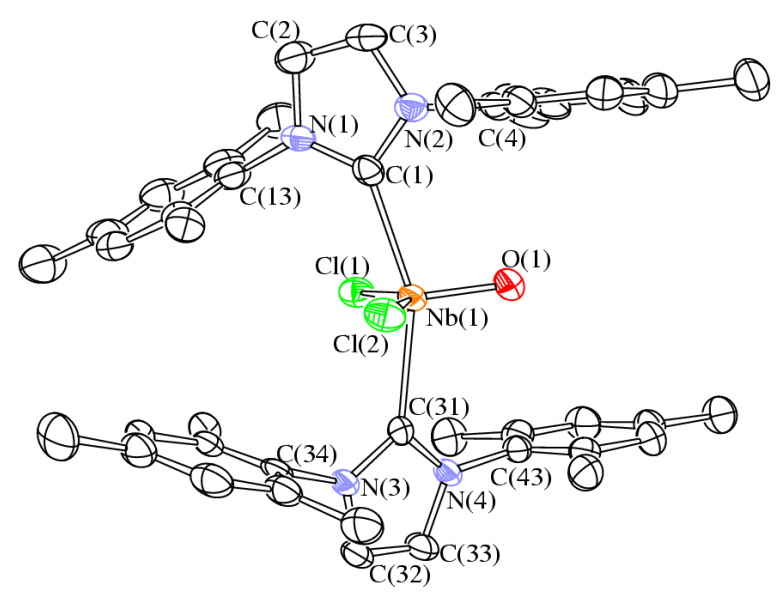

Figure 4. Molecular structure of $\mathrm{NbOCl}_{2}$ (Imes), 3, with key atoms labeled. Displacement ellipsoids are at the $50 \%$ probability level.

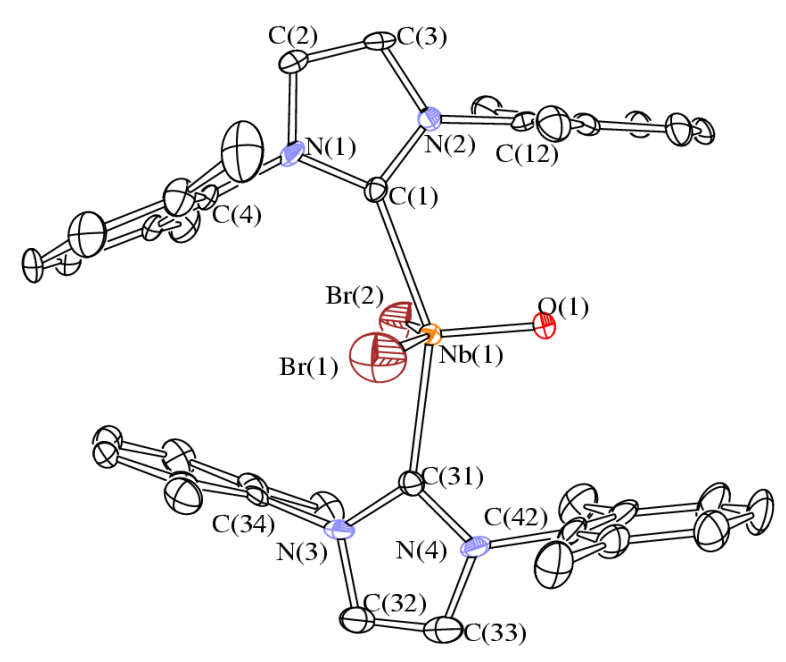


Figure 5. Molecular structure of $\mathrm{NbOBr}_{2}(\mathrm{Ixyl})$, 4, with key atoms labeled. Displacement ellipsoids are at the $50 \%$ probability level.

\begin{tabular}{ccc} 
Table 1. Selected bond distances $(\AA)$ and angles $\left(^{\circ}\right)$ for $\mathbf{3}$ and $\mathbf{4}$ \\
\hline $\mathrm{Nb}(1)-\mathrm{O}(1)$ & $1.699(4)$ & $\mathbf{4}$ \\
$\mathrm{Nb}(1)-\mathrm{X}(1)$ & $2.4425(15)$ & $1.688(5)$ \\
$\mathrm{Nb}(1)-\mathrm{X}(2)$ & $2.4348(16)$ & $2.5604(13)$ \\
$\mathrm{Nb}(1)-\mathrm{C}(1)$ & $2.322(6)$ & $2.5334(13)$ \\
$\mathrm{Nb}(1)-\mathrm{C}(31)$ & $2.332(5)$ & $2.337(7)$ \\
$\mathrm{C}(1)-\mathrm{N}(1)$ & $1.343(7)$ & $2.305(8)$ \\
$\mathrm{C}(1)-\mathrm{N}(2)$ & $1.375(7)$ & $1.353(10)$ \\
$\mathrm{N}(1)-\mathrm{C}(2)$ & $1.397(7)$ & $1.367(10)$ \\
$\mathrm{N}(2)-\mathrm{C}(3)$ & $1.395(7)$ & $1.399(11)$ \\
$\mathrm{C}(2)-\mathrm{C}(3)$ & $1.334(9)$ & $1.393(10)$ \\
$\mathrm{C}(31)-\mathrm{N}(3)$ & $1.349(7)$ & $1.331(12)$ \\
$\mathrm{C}(31)-\mathrm{N}(4)$ & $1.369(7)$ & $1.354(10)$ \\
$\mathrm{N}(3)-\mathrm{C}(32)$ & $1.384(7)$ & $1.371(10)$ \\
$\mathrm{N}(4)-\mathrm{C}(33)$ & $1.391(7)$ & $1.410(10)$ \\
$\mathrm{C}(32)-\mathrm{C}(33)$ & $1.351(9)$ & $1.374(11)$ \\
& & $1.343(13)$ \\
$\mathrm{C}(1)-\mathrm{Nb}(1)-\mathrm{C}(31)$ & $156.22(19)$ & $152.7(3)$ \\
$\mathrm{X}(1)-\mathrm{Nb}(1)-\mathrm{X}(2)$ & $144.99(6)$ & $154.45(5)$ \\
$\mathrm{C}(1)-\mathrm{Nb}(1)-\mathrm{O}(1)$ & $102.1(2)$ & $105.2(3)$ \\
$\mathrm{C}(31)-\mathrm{Nb}(1)-\mathrm{O}(1)$ & $101.66(19)$ & $102.1(3)$ \\
$\mathrm{O}(1)-\mathrm{Nb}(1)-\mathrm{X}(1)$ & $106.85(16)$ & $102.5(2)$ \\
$\mathrm{O}(1)-\mathrm{Nb}(1)-\mathrm{X}(2)$ & $108.15(16)$ & \\
\hline
\end{tabular}

The $\mathrm{Nb}(1)-\mathrm{O}(1)$ distances $[1.699(4) \AA$ for $3 ; 1.688(5)$ for 4 ] resemble other reported $\mathrm{Nb}=\mathrm{O}$ double bond distances. ${ }^{9,14,21}$ Only two Nb-NHC systems were previously crystallographically characterized. In [(C-N$\left.\left.\mathrm{C}^{\prime}\right) \mathrm{NbCl}_{3}(\mathrm{thf})\right], \mathrm{C}-\mathrm{N}-\mathrm{C}^{\prime}=2,6$-bis(imidazolylidene)pyridine, in which the binding of the NHC ligand is reinforced by multidentate coordination, the $\mathrm{Nb}(\mathrm{III})-\mathrm{C}$ distance values are around $2.20 \AA \mathrm{A}^{4 \mathrm{a}}$ On the other hand, in the complex $\mathrm{NbCl}_{5}(\mathrm{Ipr}), \mathrm{Ipr}=1,3$-bis(2,6-diisopropylphenyl)imidazol-2-ylidene, in which the NHC binding is affected by steric factors, the $\mathrm{Nb}(\mathrm{V})-\mathrm{C}$ distance is $2.396(12) \AA^{3}$ In $\mathbf{3}$ and $\mathbf{4}$, an intermediate situation is observed $[\mathrm{Nb}(1)-\mathrm{C}(1)$ : 2.322(6) $\AA$ for 3, 2.337(7) for 4; $\mathrm{Nb}(1)-\mathrm{C}(31)$ : 2.332(5) $\AA$ for $\mathbf{3}, 2.305(8)$ for 4 ]. However, the $\mathrm{Nb}-\mathrm{C}$ bonds in $\mathbf{3}$ and $\mathbf{4}$ are significantly longer than both $\mathrm{Nb}(\mathrm{IV})$ alkylidene moieties ${ }^{22}$ and even classical $\mathrm{Nb}(\mathrm{IV})$-alkyl $\sigma$-bonds. ${ }^{23}$ The carbene atoms of $\mathbf{3}$ and $\mathbf{4}$ display 
$\mathrm{C} \cdots \mathrm{X}[3.185-3.362 \AA$ for 3 ; 3.323-3.409 $\AA$ for 4$]$ and $\mathrm{C} \cdots \mathrm{O}[3.150-3.151 \AA$ for $3 ; 3.128-3.220 \AA$ for 4$]$ contacts with the terminal $\mathrm{X}$ and $\mathrm{O}$ ligands, respectively, within the sum of the van der Waals radii of the respective atoms $[\mathrm{sum}=3.45 \AA$ for $\mathrm{C} \cdots \mathrm{Cl}, 3.55 \AA$ for $\mathrm{C} \cdots \mathrm{Br}$ and $3.22 \AA$ for $\mathrm{C} \cdots \mathrm{O}] .{ }^{24}$ Similar interactions have been observed in a variety of high valent metal-halide NHC complexes, ${ }^{2 b, c, d, f, g, h}$ and have been associated with a form of $\pi$ back-donation from the halide ligands to the carbenic carbons (see below the DFT discussion).

The $\mathrm{X}(1)-\mathrm{Nb}(1)-\mathrm{X}(2)$ angle is considerably larger in $4\left[154.45(5)^{\circ}\right]$ compared to $3\left[144.99(6)^{\circ}\right]$, in view of the larger size of $\mathrm{Br} v s . \mathrm{Cl}$. In fact, $\mathrm{VOCl}_{2}(\mathrm{IMes})_{2}$ displays a $\mathrm{Cl}-\mathrm{V}-\mathrm{Cl}$ angle $\left[146.55^{\circ}\right]$ very close to that one in $3,{ }^{2 \mathrm{~d}}$ irrespective of the different nature of the central metal atom.

The dihedral angles between the two least squares planes comprising the two NHC rings are different in $3\left[49.41^{\circ}\right]$ and $4\left[27.60^{\circ}\right]$, leading to different spatial arrangements of the NHC ligands. It is plausible that this feature is the result of different packing effects in the two structures (see below DFT discussion). It is noteworthy that the corresponding dihedral angle in $\mathrm{VOCl}_{2}(\mathrm{IMes})_{2}\left[28.15^{\circ}\right]$ is very close to the one found in $\mathbf{4}$, although the V(IV) complex contains the same IMes and Cl ligands as 3.

In order to shed light on the structural and bonding features of $\mathbf{3}$ and $\mathbf{4}$, we performed DFT calculations. The calculated structures of $\mathbf{3}$ and $\mathbf{4}$ are shown in Figure 6, the caption reporting the calculated values of the main bonding parameters. The most important difference with respect to the X-Ray data concerns the dihedral angles between the two least squares planes comprising the two NHC rings. These angles have similar modulus on comparing the computed ground-state geometries of 3 and $4[\mathrm{X}=\mathrm{Cl}$ (3): experimental 49.41, calculated $31.2^{\circ} ; \mathrm{X}=\mathrm{Br}$ (4): experimental 27.60, calculated $38.3^{\circ}$ ]. This result corroborates the hypothesis that the discrepancy between $\mathbf{3}$ and $\mathbf{4}$, experimentally observed, is due to packing forces operative in the solid state (see above X-ray discussion). 

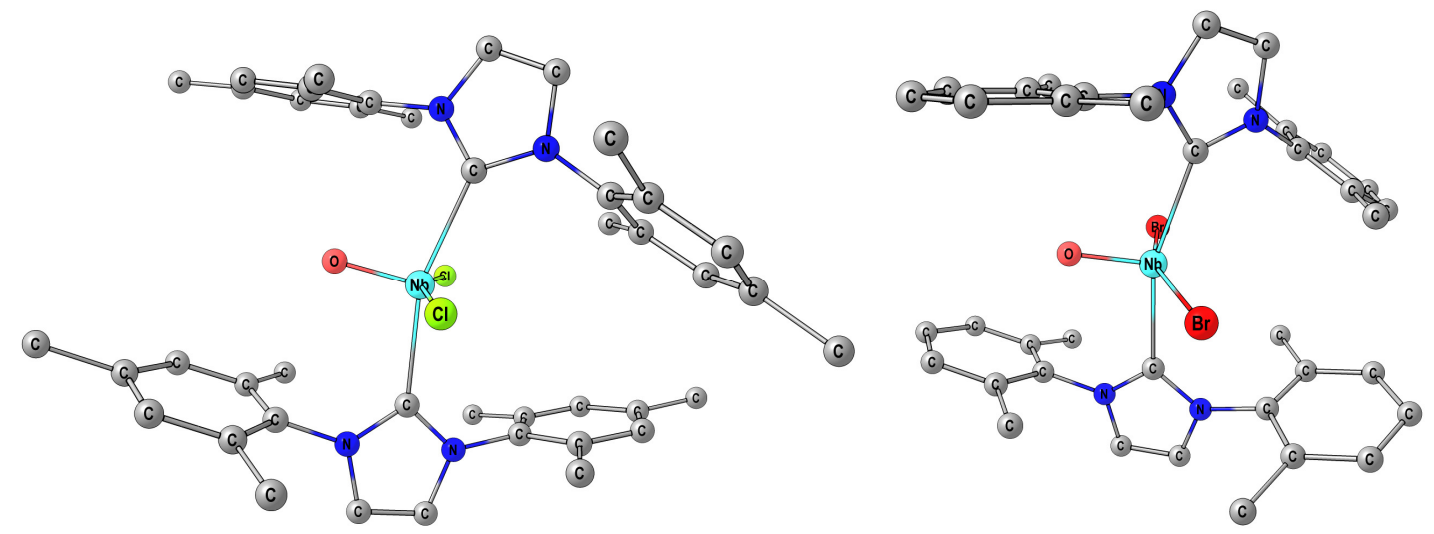

Figure 6. DFT-optimized structure of $\mathrm{NbOCl}_{2}(\mathrm{IMes})_{2}$ and $\mathrm{NbOBr}_{2}(\operatorname{Ixyl})_{2}(\mathrm{C}-\mathrm{PCM} / \omega \mathrm{B} 97 \mathrm{X}$, dichloromethane as implicit solvent). Hydrogen atoms have been omitted for clarity. Selected bond lengths for $\mathrm{NbOCl}_{2}$ (IMes) $)_{2}(\AA)$ : $\mathrm{Nb}=\mathrm{O} 1.682 ; \mathrm{Nb}-\mathrm{Cl} 2.519,2.519 ; \mathrm{Nb}-\mathrm{C} 2.366,2.366$. Selected angles for $\mathrm{NbOCl}_{2}(\mathrm{IMes})_{2}\left({ }^{\circ}\right): \mathrm{O}=\mathrm{Nb}-\mathrm{Cl} 100.5,100.5 ; \mathrm{Cl}-\mathrm{Nb}-\mathrm{Cl} 158.9 ; \mathrm{O}=\mathrm{Nb}-\mathrm{C} 99.5,99.5 ; \mathrm{C}-\mathrm{Nb}-\mathrm{C} 161.0$. Selected bond lengths for $\mathrm{NbOBr}{ }_{2}(\mathrm{Ixyl})_{2}(\AA): \mathrm{Nb}=\mathrm{O}$ 1.678; $\mathrm{Nb}-\mathrm{Br} 2.697,2.698 ; \mathrm{Nb}-\mathrm{C} 2.371,2.372$. Selected angles for $\mathrm{NbOBr}_{2}(\mathrm{Ixyl})_{2}\left({ }^{\circ}\right): \mathrm{O}=\mathrm{Nb}-\mathrm{Br} 99.8,99.8 ; \mathrm{Br}-\mathrm{Nb}-\mathrm{Br} 160.3 ; \mathrm{O}=\mathrm{Nb}-\mathrm{C} 99.9,99.9$; $\mathrm{C}-\mathrm{Nb}-\mathrm{C} 160.2$.

The metal-ligand $\sigma$-interactions in $\mathbf{3}$ are as expected for a distorted trigonal bipyramid. Niobium mainly overlaps with chloro- and carbene ligands with two perpendicular p-type orbitals $(\alpha-\mathrm{HOMO}-11 / \beta-$ HOMO-10, $\alpha$-HOMO-14/ $\beta$-HOMO-14) and one d-type orbital $(\alpha-H O M O-19 / \beta-H O M O-18)$. Other MOs, where the metal centre participates with s-, p- and d-type functions, account at the same time of $\mathrm{Nb}-\mathrm{O}, \mathrm{Nb}-\mathrm{C}$ and $\mathrm{Nb}-\mathrm{Cl} \sigma$-bonding ( $\alpha$-HOMO-21/ $\beta-\mathrm{HOMO}-19, \alpha-\mathrm{HOMO}-35 / \beta-\mathrm{HOMO}-34)$. The $\mathrm{Nb}-$ $\mathrm{O}$ bond is strongly strengthened by $\pi$-type interactions. For what concerns the $\mathrm{Nb}-\mathrm{C}$ bonds, a scarce $\pi$ overlap can be detected in $\alpha$-HOMO-17/ $\beta$-HOMO- 13 , which are orbitals mainly describing $\pi$-donation from the chloro-ligands to a d-type orbital of niobium. On considering the $\pi$-combinations of the carbene ligands involved, we can conclude that the $\sigma-\mathrm{Nb}-\mathrm{C}$ bonds are supported by a weak $\mathrm{NHC}$ to $\mathrm{Nb} \pi$ donation (see the X-ray discussion). $\alpha$-HOMO is the antibonding counterpart of $\alpha$-HOMO-17 and holds $\pi^{*} \mathrm{Nb}-\mathrm{Cl}$ character. The contribution of the donor carbon atoms to this last $\mathrm{MO}$ is negligible. Figure 7 shows the $\alpha$-MOs discussed in this section. 


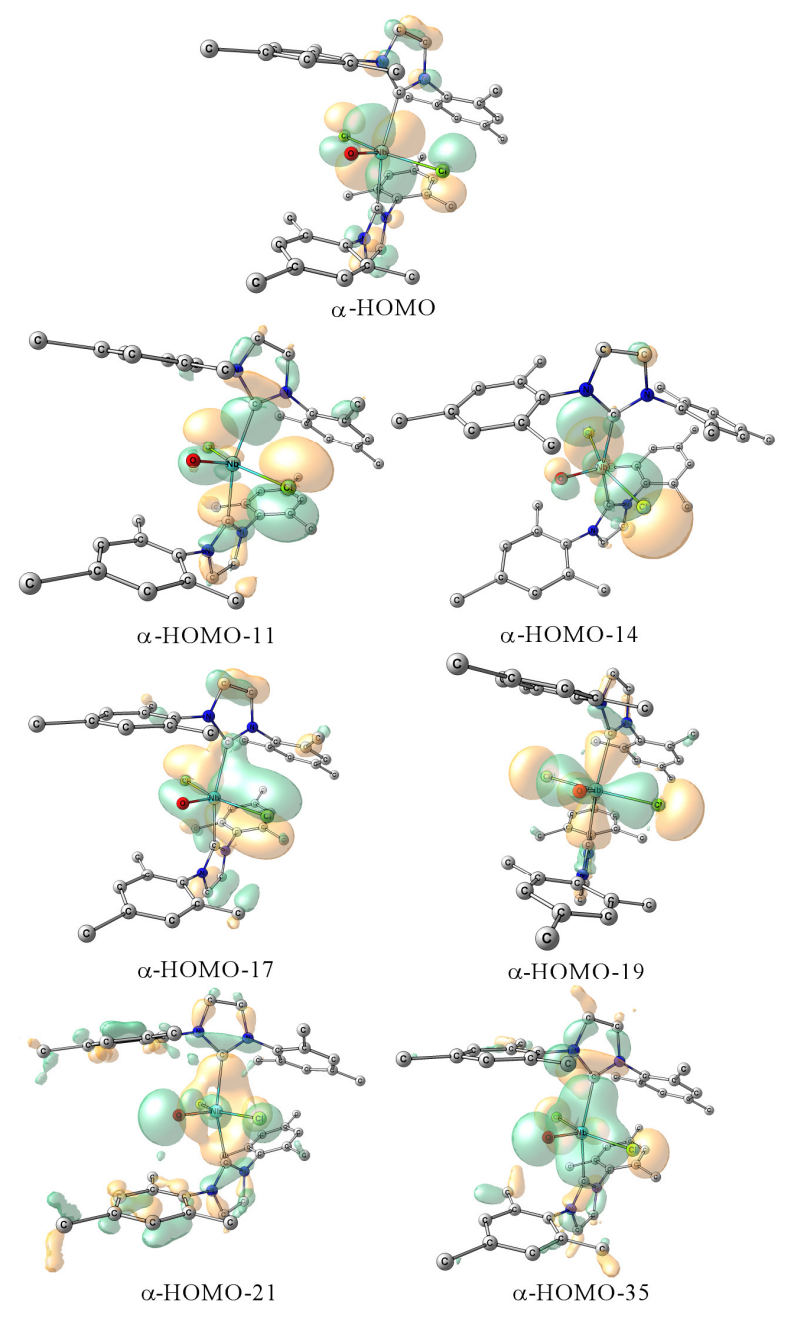

Figure 7. Selected occupied $\alpha$-MOs computed for $\mathrm{NbOCl}_{2}(\mathrm{IMes})_{2}, \mathbf{3}$. $\mathrm{C}-\mathrm{PCM} / \omega \mathrm{B} 97 \mathrm{X}$ calculations, surface isovalue $=0.025$ a.u. Hydrogen atoms have been omitted for clarity.

The metal-ligands $\sigma$-type interactions found for $\mathbf{4}$ are qualitatively comparable to the ones in $\mathbf{3}$. The $\pi$ bonds of niobium with the two carbenes are mainly accounted by the $\alpha$-HOMO-15/ $\beta-H O M O-13$ orbitals. In these MOs, a strong contribution from the two halogens can be observed, as described for 3 . The additional strength of the $\mathrm{Nb}-\mathrm{C}$ bonds supplied by $\pi$ contribution, as ascertained by computer outcomes, is in alignment with the experimental detection of $\mathrm{C}$ (carbene) $-\mathrm{X}$ interactions in the $\mathrm{X}$-ray structures of 3-4. The comparison of the $\alpha-\mathrm{HOMO}-17 / \beta-\mathrm{HOMO}-13$ orbitals of 3 and the $\alpha-\mathrm{HOMO}-$ $15 / \beta$-HOMO-13 orbitals of 4 (Figure 8 ) evidences a greater $\mathrm{Nb}-\mathrm{C} \pi$-overlap in the case of the bromo- 
derivative 4. It is however to be highlighted that the calculated dissociation of one carbene moiety, according to the general reaction $\mathrm{NbOX}_{2}(\mathrm{NHC})_{2} \rightarrow \mathrm{NbOX}_{2}(\mathrm{NHC})+\mathrm{NHC}$, is featured by comparable Gibbs energy variations for $3\left(11.8 \mathrm{kcal} \mathrm{mol}^{-1}\right)$ and $\mathbf{4}\left(12.6 \mathrm{kcal} \mathrm{mol}^{-1}\right)$, respectively.

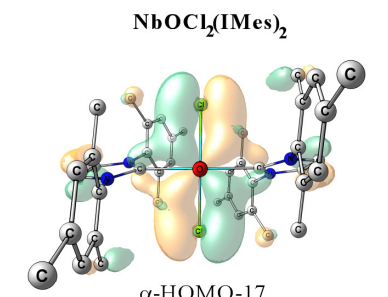

$\alpha-\mathrm{HOMO}-17$

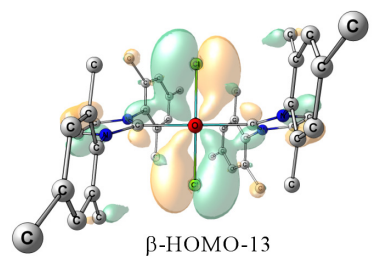

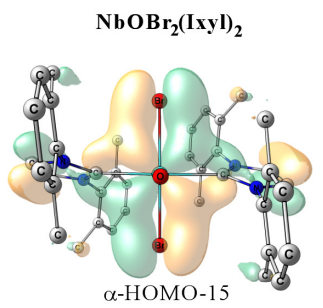

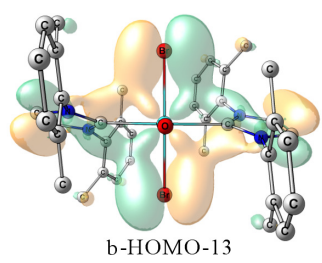

Figure 8. Comparison of selected occupied MOs computed for $\mathrm{NbOCl}_{2}$ (IMes) $)_{2}$ and $\mathrm{NbOBr}_{2}(\mathrm{Ixyl})_{2}$. C-PCM/ $/ \omega \mathrm{B} 97 \mathrm{X}$ calculations, surface isovalue $=0.025$ a.u. Hydrogen atoms have been omitted for clarity.

We attempted a series of nucleophilic substitution reactions on the $\mathrm{Nb}$ (IV) dichloride complex $\mathbf{2 b}$. We found that one chloride ligand could be displaced by an alkoxide (aryloxide) group. Thus the novel compounds $\mathrm{NbOCl}(\mathrm{OR})(\mathrm{R}=\mathrm{Ph}, \mathbf{5} ; \mathrm{Me}, \mathbf{6})$ were obtained from $\mathbf{2 b}$ and $\mathrm{NaOR}(1: 1$ molar ratio $)$ in tetrahydrofuran, and isolated after work up in 53-65\% yields (Scheme 3). The reaction of $\mathbf{2 b}$ with even an excess of $\mathrm{NaOPh}$ cleanly led to $\mathbf{5}$, while the reaction of $\mathbf{2 b}$ with two equivalents of $\mathrm{NaOMe}$ presumably afforded a mixture of 6 and $\mathrm{NbO}(\mathrm{OMe})_{2}$.

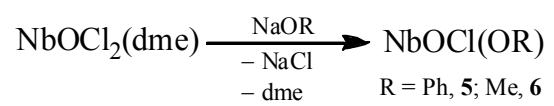

Scheme 3. Preparation of methoxide and phenoxide derivatives of $\mathrm{Nb}(\mathrm{IV})$ 
5 and $\mathbf{6}$ are neutral compounds that, according to the elemental analyses and the NMR spectra recorded on the respective samples treated with water do not contain dme or thf units (see Experimental for details). ${ }^{25}$ We propose that the structure of 5-6 resembles that of $\mathrm{NbOCl}_{2}$, with one chloride ligand per metal centre replaced by one OR group. The structure of $\mathrm{NbOCl}_{2}$ consists of chains of $\mathrm{NbOCl}_{4}$ pyramids sharing their opposite edges, the distinct chains being linked by $\mathrm{Nb}=\mathrm{O}---\mathrm{Nb}$ contacts. ${ }^{10 \mathrm{c}, 11 \mathrm{a}}$ Analogously to the case of $\mathrm{NbCl}_{4}$, each chain shows an alternation of two different $\mathrm{Nb}-\mathrm{Nb}$ distances, resulting in properties such as semiconduction and diamagnetisms. ${ }^{26}$ Following the hypothesis of a $\mathrm{NbOCl}_{2}$ type structure, we optimized by DFT the geometry of a four chain unit for both $\mathbf{5}$ and $\mathbf{6}$. Views of these structures, obtained considering four unpaired electrons, are reported in Figures 9 and 10, together with the respective spin density surfaces. Attempts to optimize these compounds with lower multiplicity afforded only distorted and high-energy geometries. As expected, the unpaired electrons resulted localized on d-type orbitals of the metal centers. The computed $\mathrm{Nb}^{\cdots \cdots} \mathrm{Nb}$ distances between the two central units are 3.666 and $3.675 \AA$ for $\mathrm{R}=\mathrm{Me}$ and $\mathrm{R}=\mathrm{Ph}$, respectively. The corresponding average $\mathrm{Nb}^{\cdots \cdots} \mathrm{Nb}$ distances in the two models are 3.678 and $3.687 \AA$. These values are comparable to those reported for similar niobium(IV) coordination polymers in the absence of direct metal-metal interaction. $^{10 \mathrm{c}}$

In agreement with the DFT calculations, $\mathbf{5}$ and $\mathbf{6}$ are paramagnetic compounds, the magnetic susceptibility values being consistent with the presence of isolated $\mathrm{Nb}(\mathrm{IV})$ centers. ${ }^{15}$ The IR absorption due to the $\mathrm{Nb}=\mathrm{O}$ moiety has been detected around $800 \mathrm{~cm}^{-1}$, in analogy with what previously found for $\mathrm{NbOCl}_{2}\left(\mathrm{~cm}^{-1}\right) .^{27}$ 


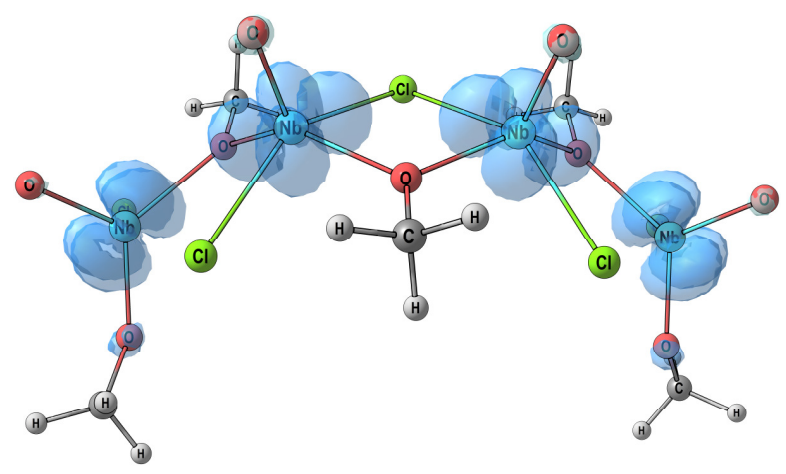

Figure 9. DFT-optimized structure $(\omega \mathrm{B} 97 \mathrm{X}$ functional $)$ of $[\mathrm{NbOCl}(\mathrm{OMe})(\mu$ $\mathrm{Cl})(\mu-\mathrm{OMe}) \mathrm{NbO}(\mu-\mathrm{Cl})(\mu-\mathrm{OMe}) \mathrm{NbO}(\mu-\mathrm{Cl})(\mu-\mathrm{OMe}) \mathrm{NbO}(\mathrm{Cl})(\mathrm{OMe})]^{2-}$ and spin density surface (isovalue $=0.01$ a.u.). Selected bond lengths for the central subunits $(\AA): \quad \mathrm{Nb}=\mathrm{O} \quad 1.683,1.684 ; \quad \mathrm{Nb}-(\mu-\mathrm{Cl}) \quad 2.584,2.584$; $\mathrm{Nb}-(\mu-\mathrm{O}) 2.153,2.155 ; \mathrm{Nb}---\mathrm{Nb} 3.666$.

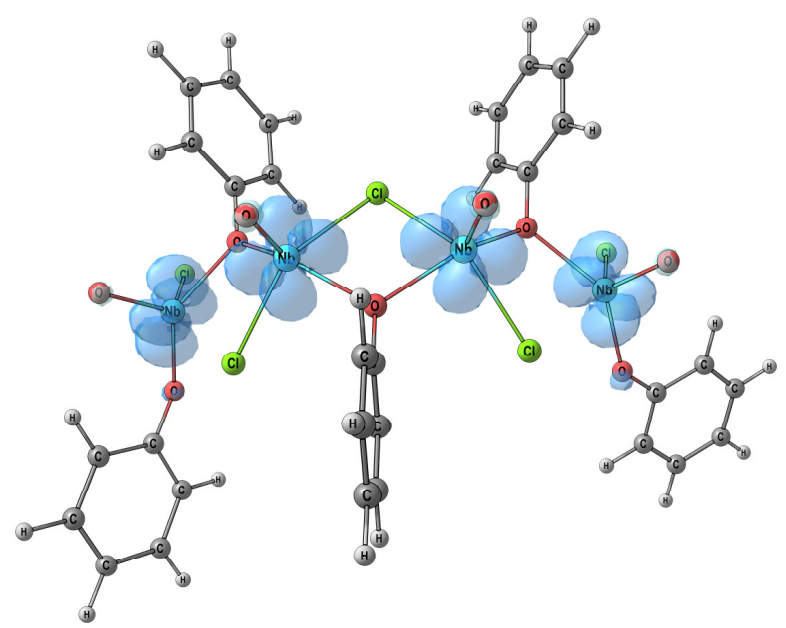

Figure 10. DFT-optimized structure $(\omega \mathrm{B} 97 \mathrm{X}$ functional) of $[\mathrm{NbOCl}(\mathrm{OPh})(\mu-$ $\mathrm{Cl})(\mu-\mathrm{OPh}) \mathrm{NbO}(\mu-\mathrm{Cl})(\mu-\mathrm{OPh}) \mathrm{NbO}(\mu-\mathrm{Cl})(\mu-\mathrm{OPh}) \mathrm{NbO}(\mathrm{Cl})(\mathrm{OPh})]^{2-}$ and spin density surface (isovalue $=0.01$ a.u.). Selected bond lengths for the central subunits $(\AA): \mathrm{Nb}=\mathrm{O} 1.678,1.678 ; \mathrm{Nb}-(\mu-\mathrm{Cl}) 2.566,2.569 ; \mathrm{Nb}-(\mu-\mathrm{O}) 2.170$, $2.170 ; \mathrm{Nb}---\mathrm{Nb} 3.675$.

\section{Conclusions}

The coordination chemistry of NHC ligands to oxophilic, early transition metal complexes has received less attention that the corresponding chemistry with late transition metals. In particular, very few niobium-NHC complexes have been structurally characterized up to now. In the present paper, we have described a route to the synthesis of niobium(IV) oxide dihalides complexes, which have been 
almost unknown so far. These products may represent starting materials for the preparation of a variety of $\mathrm{Nb}(\mathrm{IV})$ compounds containing an oxide ligand. In particular, fairly air stable $\mathrm{Nb}(\mathrm{IV})-\mathrm{NHC}$ coordination adducts have been obtained and crystallographically characterized. According to X-ray and DFT outcomes, the $\mathrm{Nb}-\mathrm{C}($ carbene) bonds consist of a $\sigma$ NHC to metal donation, reinforced by a $\pi$ metal to $\mathrm{NHC}$ contribution, involving the halide ligands.

\section{Experimental Section.}

General: Warning: the metal compounds reported in this paper are highly moisture-sensitive, thus rigorously anhydrous conditions were required for the reaction, crystallization and separation procedures. The reaction vessels were oven dried at $150{ }^{\circ} \mathrm{C}$ prior to use, evacuated $\left(10^{-2} \mathrm{mmHg}\right)$ and then filled with argon. $\mathrm{NbCl}_{5}(99+\%$ purity) was purchased from Strem and stored under argon atmosphere as received. $\mathrm{NbBr}_{5},{ }^{28} \mathrm{NbOCl}_{3},{ }^{8 \mathrm{c}}$ Imes and Ixyl ${ }^{29}$ were prepared according to the respective literature procedures. All the organic reactants were commercial products (Sigma Aldrich or Apollo Sci.) of the highest purity available. Solvents (Sigma Aldrich) were distilled over appropriate drying agents under argon atmosphere before use. Infrared spectra were recorded at $298 \mathrm{~K}$ on a FT IR-Perkin Elmer Spectrometer, equipped with UATR sampling accessory. Conductivity measurements were carried out using an Eutech Con 700 instrument (cell constant $\left.=1.0 \mathrm{~cm}^{-1}\right){ }^{30} \mathrm{UV}$-vis spectra were recorded with an Ultrospec 2100 Pro spectrophotometer. EPR spectra were recorded at $298 \mathrm{~K}$ on a Varian (Palo Alto, CA, USA) E112 spectrometer operating at X band, equipped with a Varian E257 temperature control unit and interfaced to IPC 610/P566C industrial grade Advantech computer, using acquisition board ${ }^{31}$ and software package especially designed for EPR experiments. ${ }^{32}$ Experimental EPR spectra were simulated by the WINSIM 32 program. ${ }^{33}$ Magnetic susceptibilities (reported per metal atom) were measured at $298 \mathrm{~K}$ on solid samples with a Magway MSB Mk1 magnetic susceptibility balance (Sherwood Scientific Ltd.). Diamagnetic corrections were introduced according to König. ${ }^{34}$ 
NMR spectra were recorded at $298 \mathrm{~K}$ on a Bruker Avance II DRX400 instrument equipped with a BBFO broadband probe. The chemical shifts for ${ }^{1} \mathrm{H}$ and ${ }^{13} \mathrm{C}$ were referenced to the non-deuterated aliquot of the solvent, while the chemical shifts for ${ }^{93} \mathrm{Nb}$ were referenced to external $\left[\mathrm{NEt}_{4}\right]\left[\mathrm{NbCl}_{6}\right]$. The ${ }^{1} \mathrm{H}$ and ${ }^{13} \mathrm{C}$ NMR spectra were assigned with the assistance of ${ }^{1} \mathrm{H},{ }^{13} \mathrm{C}$ correlation measured through $g s$-HSQC and $g s-\mathrm{HMBC}$ experiments. ${ }^{35}$ Carbon, hydrogen and nitrogen analyses were performed on a Carlo Erba mod. 1106 instrument. The halide content was determined by the Mohr method ${ }^{36}$ on solutions prepared by dissolution of the solid in aqueous $\mathrm{KOH}$ at boiling temperature, followed by cooling to room temperature and addition of $\mathrm{HNO}_{3}$ up to neutralization. Niobium was analyzed as $\mathrm{Nb}_{2} \mathrm{O}_{5}$, obtained by hydrolysis of the samples followed by calcination in a platinum crucible.

Synthesis and isolation of $\mathbf{N b O B r}_{3}$. A suspension of $\mathrm{NbBr}_{5}(6.40 \mathrm{~g}, 0.0130 \mathrm{~mol})$ in $\mathrm{CH}_{2} \mathrm{Cl}_{2}(50 \mathrm{~mL})$ was treated with $\mathrm{O}\left(\mathrm{SiMe}_{3}\right)_{2}(2.76 \mathrm{~mL}, 0.0130 \mathrm{mmol})$. The mixture was stirred at room temperature for $48 \mathrm{~h}$, during which progressive color turning of the mixture from brick-red to yellow was noticed. Then the volatile materials were removed under vacuum, and the residue was washed with pentane $(2 \times 30$ $\mathrm{mL}$ ). The product was isolated as a yellow powder. Yield $3.67 \mathrm{~g}, 81 \%$. Anal. Calcd. for $\mathrm{Br}_{3} \mathrm{NbO}: \mathrm{Nb}$, 26.65; $\mathrm{Br}, 68.76$. Found: $\mathrm{Nb}, 26.30 ; \mathrm{Br}, 69.06$. IR (solid state): $v=740 \mathrm{vs}(\mathrm{Nb}=\mathrm{O}) \mathrm{cm}^{-1}$.

Synthesis and isolation of $\mathbf{N b O B r}_{\mathbf{3}}(\mathbf{d m e}), \mathbf{1 b} . \mathrm{NbOBr}_{3}(225 \mathrm{mg}, 0.645 \mathrm{mmol})$ was suspended in toluene $(10 \mathrm{~mL})$, then dme $(0.093 \mathrm{~mL}, 0.90 \mathrm{mmol})$ was added. A red solution formed in a few minutes, and this solution was stirred for additional 30 minutes. Addition of pentane $(30 \mathrm{~mL})$ determined the precipitation of a yellow solid. The solid was isolated and dried under vacuum. Yield $198 \mathrm{mg}, 70 \%$. Anal. Calcd. for $\mathrm{C}_{4} \mathrm{H}_{10} \mathrm{Br}_{3} \mathrm{NbO}_{3}$ : C, 10.95; H, 2.30; Nb, 21.18; Br, 54.64. Found: C, 11.07; H, 2.21; Nb, 21.03; $\mathrm{Br}, 54.45$. IR (solid state): $v=2943 \mathrm{w}, 1464 \mathrm{w}, 1456 \mathrm{w}, 1446 \mathrm{w}-\mathrm{m}, 1276 \mathrm{w}, 1240 \mathrm{w}, 1185 \mathrm{w}, 1075 \mathrm{~m}$, 
1020vs $(\mathrm{Nb}=\mathrm{O}), 989 \mathrm{~m}, 959 \mathrm{~s}, 859 \mathrm{~s}, 824 \mathrm{w}, 759 \mathrm{vs} \mathrm{cm}{ }^{-1} .{ }^{1} \mathrm{H}$ NMR $\left(\mathrm{CD}_{2} \mathrm{Cl}_{2}\right): \delta=4.15\left(\mathrm{~s}, 2 \mathrm{H}, \mathrm{CH}_{2}\right), 4.14$ ppm (s, 3H, $\left.\mathrm{CH}_{3}\right) .{ }^{13} \mathrm{C}\left\{{ }^{1} \mathrm{H}\right\} \mathrm{NMR}\left(\mathrm{CD}_{2} \mathrm{Cl}_{2}\right): \delta=75.6,70.5\left(\mathrm{CH}_{2}\right) ; 70.3,63.6 \mathrm{ppm}\left(\mathrm{CH}_{3}\right) .{ }^{93} \mathrm{Nb} \mathrm{NMR}$ $\left(\mathrm{CD}_{2} \mathrm{Cl}_{2}\right): \delta=-205 \mathrm{ppm}\left(\Delta v^{1 / 2}=1.510^{3} \mathrm{~Hz}\right) . \mathrm{UV}-\mathrm{Vis}\left(\mathrm{CH}_{2} \mathrm{Cl}_{2}\right): \lambda_{\max } / \mathrm{nm}\left(\varepsilon / \mathrm{M}^{-1} \mathrm{~cm}^{-1}\right)=335(10)$ 387(7), 444(8).

\section{Synthesis and isolation of $\mathrm{NbOX}_{2}(\mathrm{dme})(\mathrm{X}=\mathrm{Cl}, 2 \mathrm{2a} ; \mathrm{X}=\mathrm{Br}, 2 \mathrm{~b})$.}

A suspension of $\mathrm{NbOCl}_{3}(380 \mathrm{mg}, 1.77 \mathrm{mmol})$ in toluene $(20 \mathrm{~mL})$ was treated with dme $(0.21 \mathrm{~mL}, 2.0$ mmol). A light-yellow solution was obtained in 5 minutes. This solution was cooled with an ice bath, then $\mathrm{SnBu}_{3} \mathrm{H}(0.48 \mathrm{~mL}, 1.8 \mathrm{mmol})$ was added dropwise. The mixture was allowed to warm to room temperature, and stirred for additional $18 \mathrm{~h}$. A dark-blue precipitate was formed below a green-blue solution. The solid (2a) was isolated, washed with pentane $(15 \mathrm{~mL})$ and then dried under vacuum. Yield $291 \mathrm{mg}, 61 \%$. Anal. Calcd. for $\mathrm{C}_{4} \mathrm{H}_{10} \mathrm{Cl}_{2} \mathrm{NbO}_{3}$ : C, 17.80; H, 3.73; $\mathrm{Nb}, 34.42 ; \mathrm{Cl}, 26.27$. Found: $\mathrm{C}$, 17.69; H, 3.75; Nb, 34.20; Cl, 26.12. IR (solid state): $v=2949 \mathrm{w}, 2847 \mathrm{vw}, 1454 \mathrm{~m}, 1242 \mathrm{w}, 1191 \mathrm{w}$, $1076 \mathrm{~m}, 1025 \mathrm{~s}(\mathrm{Nb}=\mathrm{O}), 957 \mathrm{~m}, 866 \mathrm{~m}-\mathrm{sh}, 838 \mathrm{~s}, 804 \mathrm{vs}, 771 \mathrm{~s}, 701 \mathrm{~m} \mathrm{~cm}^{-1}$. Magnetic measurement: $\chi_{\mathrm{M}}{ }^{\text {corr }}=$ $7.94 \times 10^{-4} \mathrm{cgsu}, \mu_{\text {eff }}=1.40 \mathrm{BM}$. UV-Vis (THF): $\lambda_{\max } / \mathrm{nm}\left(\varepsilon / \mathrm{M}^{-1} \mathrm{~cm}^{-1}\right)=278\left(6 \cdot 10^{2}\right), 632(9), 741(10)$. Compound $\mathbf{2 b}$ was obtained by a procedure similar to that described for $\mathbf{2 a}$, from $\mathrm{NbOBr}_{3}(514 \mathrm{mg}, 1.47$ mmol $)$, dme $(0.60 \mathrm{~mL}, 5.8 \mathrm{mmol})$ and $\mathrm{SnBu}_{3} \mathrm{H}(0.40 \mathrm{~mL}, 1.5 \mathrm{mmol})$. The final dark-blue solution in toluene was added of pentane $(30 \mathrm{~mL})$ in order to obtain $\mathbf{2 b}$ as a dark precipitate. Yield $343 \mathrm{mg}, 65 \%$. Anal. Calcd. for $\mathrm{C}_{4} \mathrm{H}_{10} \mathrm{Br}_{2} \mathrm{NbO}_{3}$ : C, 13.39; H, 2.81; Nb, 25.89; Br, 44.54. Found: C, 13.27; H, 2.72; $\mathrm{Nb}$, 25.60; $\mathrm{Br}, 42.88$. IR (solid state): $v=2943 \mathrm{w}, 2845 \mathrm{w}, 1447 \mathrm{~m}, 1258 \mathrm{w}, 1187 \mathrm{w}, 1076 \mathrm{~m}, 1018 \mathrm{~s}(\mathrm{Nb}=\mathrm{O})$, $953 \mathrm{~m}-\mathrm{s}, 849 \mathrm{~s}, 799 \mathrm{~s}, 755 \mathrm{vs}, 695 \mathrm{~s} \mathrm{~cm}^{-1}$. Magnetic measurement: $\chi_{\mathrm{M}}{ }^{\text {corr }}=1.13 \times 10^{-3} \mathrm{cgsu}, \mu_{\text {eff }}=1.65 \mathrm{BM}$. UV-Vis (THF): $\lambda_{\max } / \mathrm{nm}\left(\varepsilon / \mathrm{M}^{-1} \mathrm{~cm}^{-1}\right)=351\left(5 \cdot 10^{2}\right), 461(20), 609(12), 722(10), 805\left(3 \cdot 10^{2}\right)$ 


\section{Synthesis and isolation of $\mathrm{NbOCl}_{2}(\text { thf })_{2}, 2 \mathrm{c}$.}

This product was obtained by the same procedure described for $\mathbf{2 b}$, from $\mathrm{NbOCl}_{3}(249 \mathrm{mg}, 1.16 \mathrm{mmol})$, thf $(0.21 \mathrm{~mL}, 2.6 \mathrm{mmol})$ and $\mathrm{SnBu}_{3} \mathrm{H}(0.31 \mathrm{~mL}, 1.2 \mathrm{mmol})$. Dark-blue solid, yield $195 \mathrm{mg}(52 \%)$. Anal. Calcd. for $\mathrm{C}_{8} \mathrm{H}_{16} \mathrm{Cl}_{2} \mathrm{NbO}_{3}$ : C, 29.65; H, 4.98; Nb, 28.67; Cl, 21.88. Found: C, 29.31; H, 4.75; Nb, 28.89; $\mathrm{Cl}, 21.60$. IR (solid state): $v=2955 \mathrm{w}, 2926 \mathrm{w}, 2872 \mathrm{~s}, 1455 \mathrm{w}-\mathrm{m}, 1251 \mathrm{w}, 1005 \mathrm{~m}, 892 \mathrm{~s}, 812 \mathrm{vs}, 672 \mathrm{vs}$ $(\mathrm{Nb}-\mathrm{O}-\mathrm{Nb}) \mathrm{cm}^{-1}$. Magnetic measurement: $\chi_{\mathrm{M}}{ }^{\text {corr }}=5.88 \times 10^{-4}$ cgsu, $\mu_{\text {eff }}=1.19 \mathrm{BM}$. UV-Vis $\left(\mathrm{CH}_{2} \mathrm{Cl}_{2}\right)$ : $\lambda_{\max } / \mathrm{nm}\left(\varepsilon / \mathrm{M}^{-1} \mathrm{~cm}^{-1}\right)=270\left(5 \cdot 10^{2}\right), 716(5), 746(7)$.

\section{Synthesis and isolation of $\mathrm{NbOCl}_{2}(\mathrm{Imes})_{2}, 3$.}

A suspension of $\mathrm{NbOCl}_{3}(230 \mathrm{mg}, 1.07 \mathrm{mmol})$ in toluene $(15 \mathrm{~mL})$ was treated with $\mathrm{MeCN}(0.13 \mathrm{~mL}, 2.5$ mmol). The resulting light yellow solution was cooled with an ice bath, then $\mathrm{SnBu}_{3} \mathrm{H}(0.29 \mathrm{~mL}, 1.1$ mmol) was added dropwise. The mixture was allowed to warm to room temperature, and stirred for additional 30 minutes. The resulting dark-blue precipitate was formed in a green-blue solution, which was eliminated with a syringe. The solid was washed with toluene $(20 \mathrm{~mL})$. Thus, toluene $(15 \mathrm{~mL})$ and Imes $(660 \mathrm{mg}, 2.17 \mathrm{mmol})$ were added in the order given. The mixture was stirred for $2 \mathrm{~h}$ at $50{ }^{\circ} \mathrm{C}$, then it was allowed to cool to room temperature. The final solution was concentrated, layered with pentane and settled aside at $-30{ }^{\circ} \mathrm{C}$; a microcrystalline brown material was obtained after 24 hours. Yield 515 $\mathrm{mg}, 61 \%$. Crystals suitable for X-ray analysis were collected from a toluene/hexane mixture at $-30{ }^{\circ} \mathrm{C}$. Anal. Calcd. for $\mathrm{C}_{42} \mathrm{H}_{48} \mathrm{Cl}_{2} \mathrm{~N}_{4} \mathrm{NbO}$ : C, 63.96; H, 6.13; N, 7.10; Nb, 11.78; Cl, 8.99. Found: C, 63.60; H, 6.22; N, 7.03; Nb, 12.01; Cl, 8.58. IR (solid state): $v=2920 \mathrm{~m}, 2855 \mathrm{w}-\mathrm{m}, 2760 \mathrm{w}-\mathrm{br}, 1675 \mathrm{w}, 1605 \mathrm{~m}$, $1587 \mathrm{w}, 1540 \mathrm{~m}, 1483 \mathrm{~m}-\mathrm{s}, 1457 \mathrm{~m}, 1380 \mathrm{w}, 1319 \mathrm{w}, 1262 \mathrm{w}, 1230 \mathrm{~s}, 1163 \mathrm{w}, 1100 \mathrm{w}, 1035 \mathrm{~m}(\mathrm{Nb}=\mathrm{O})$, 930m, 851s, 756w, 732m, 695w, 677m cm $\mathrm{m}^{-1}$. EPR (solid state): $\mathrm{g}_{/ /}=2.214, \mathrm{~A}_{/ /}=163.7 \mathrm{G} ; \mathrm{g}_{\perp}=2.412$, 
$\mathrm{A}_{\perp}=60.9$ G. Magnetic measurement: $\chi_{\mathrm{M}}{ }^{\text {corr }}=1.21 \times 10^{-3}$ cgsu, $\mu_{e f f}=1.70 \mathrm{BM}$. UV-Vis (toluene): $\lambda_{\max } / \mathrm{nm}\left(\varepsilon / \mathrm{M}^{-1} \mathrm{~cm}^{-1}\right)=373(80), 716(20)$.

\section{Synthesis and isolation of $\mathrm{NbOBr}_{2}(\mathrm{Ixyl})_{2}, 4$.}

A suspension of $\mathrm{NbOBr}_{3}(198 \mathrm{mg}, 0.568 \mathrm{mmol})$ in toluene $(10 \mathrm{~mL})$ was treated with dme $(0.062 \mathrm{~mL}$, $0.60 \mathrm{mmol})$. A light-yellow solution was obtained in a few minutes. This solution was cooled with an ice bath, then $\mathrm{SnBu}_{3} \mathrm{H}(0.15 \mathrm{~mL}, 0.57 \mathrm{mmol})$ was added dropwise. The mixture was allowed to warm to room temperature, and stirred for additional $18 \mathrm{~h}$. Pentane $(25 \mathrm{~mL})$ was added in order to allow the precipitation of a dark-blue solid from a green-blue solution, which was eliminated with a syringe. Thus, toluene $(15 \mathrm{~mL})$ and Ixyl $(330 \mathrm{mg}, 1.19 \mathrm{mmol})$ were added in the order given. The mixture was stirred for $4 \mathrm{~h}$ at $50{ }^{\circ} \mathrm{C}$, then it was allowed to cool to room temperature and filtrated in order to remove some solid. The filtrated solution was eliminated of the volatiles, hence crystallization of the residue from toluene/pentane afforded a dark brown solid which was washed with pentane $(2 \times 20 \mathrm{~mL})$ and dried in vacuum. Yield $233 \mathrm{mg}, 50 \%$. Crystals suitable for X-ray analysis were collected from a toluene/hexane mixture settled aside at $-30{ }^{\circ} \mathrm{C}$. Anal. Calcd. for $\mathrm{C}_{38} \mathrm{H}_{40} \mathrm{Br}_{2} \mathrm{~N}_{4} \mathrm{NbO}$ : C, 55.56; H, 4.91; N, 6.82; Nb, 11.31; Br, 19.45. Found: C, 55.63; H, 5.02; N, 6.66; Nb, 11.12; Br, 19.28. IR (solid state): $v=3163 \mathrm{w}$, 3132w, 3026w, 2917w-m, 1687w, 1603w, 1532w-m, 1472s, 1446m-sh, 1392w-m, 1380m, 1276m, $1215 \mathrm{~m}, 1167 \mathrm{w}-\mathrm{m}, 1100 \mathrm{~m}, 1035 \mathrm{~m}(\mathrm{Nb}=\mathrm{O}), 960 \mathrm{~m}, 948 \mathrm{~s}, 923 \mathrm{~m}, 866 \mathrm{~m}, 770 \mathrm{vs}, 730 \mathrm{vs}, 695 \mathrm{vs} \mathrm{cm}^{-1}$. Magnetic measurement: $\chi_{\mathrm{M}}{ }^{\text {corr }}=9.42 \times 10^{-4} \mathrm{cgsu}, \mu_{\text {eff }}=1.50 \mathrm{BM}$. EPR (solid state): $\mathrm{g}_{/ /}=2.219, \mathrm{~A}_{/ /}=$ $176.5 \mathrm{G} ; \mathrm{g}_{\perp}=2.331, \mathrm{~A}_{\perp}=73.8 \mathrm{G} . \mathrm{UV}-\mathrm{Vis}$ (toluene): $\lambda_{\max } / \mathrm{nm}\left(\varepsilon / \mathrm{M}^{-1} \mathrm{~cm}^{-1}\right)=320\left(2.0 \cdot 10^{3}\right), 384$ $\left(1.0 \cdot 10^{3}\right), 480\left(2.5 \cdot 10^{2}\right)$. 
Synthesis of $\operatorname{NbOCI}(\mathrm{OR})(\mathbf{R}=\mathbf{P h}, \mathbf{5}$; Me, 6). A solution of freshly prepared 2 a (from $1.10 \mathrm{mmol}$ of $\left.\mathrm{NbOCl}_{3}\right)$ in tetrahydrofuran $(20 \mathrm{~mL})$ was treated with $\mathrm{NaOPh}(128 \mathrm{mg}, 1.10 \mathrm{mmol})$. An immediate color change from deep blue to brown was observed, and the mixture was left stirring at room temperature for additional $18 \mathrm{~h}$. Thus the volatiles were removed under vacuum, and the resulting residue was dissolved in toluene $(30 \mathrm{~mL})$. The solution was filtered in order to remove some insoluble material, then the solvent was removed under vacuum. The residue was washed with pentane $(2 \times 20 \mathrm{~mL})$, thus compound 5 was obtained as a light brown powder. Yield $170 \mathrm{mg}$ (65\%). An aliquot (ca. $20 \mathrm{mg}$ ) was dissolved into $\mathrm{CDCl}_{3}(0.7 \mathrm{~mL})$, treated with a large excess of $\mathrm{H}_{2} \mathrm{O}$ and allowed to contact with air overnight; subsequent ${ }^{1} \mathrm{H}$ NMR spectrum of the solution pointed out the presence of $\mathrm{PhOH}$ and traces of thf. Anal. Calcd. for $\mathrm{C}_{6} \mathrm{H}_{5} \mathrm{ClNbO}_{2}$ : C, 30.35; H, 2.12; Nb, 39.12; Cl, 14.93. Found: C, 30.16; H, 2.18; Nb, 39.02; Cl, 14.76. IR (solid state): $v=3061 \mathrm{w}, 2958 \mathrm{w}, 1586 \mathrm{~m}, 1477 \mathrm{~s}, 1451 \mathrm{w}-\mathrm{sh}, 1238 \mathrm{~s}, 1160 \mathrm{~m}, 1098 \mathrm{w}, 1067 \mathrm{w}$, $1020 \mathrm{w}, 1000 \mathrm{w}, 884 \mathrm{~m}, 795 \mathrm{~s}(\mathrm{Nb}=\mathrm{O}), 749 \mathrm{vs}, 685 \mathrm{vs} \mathrm{cm}^{-1}$. Magnetic measurement: $\chi_{\mathrm{M}}{ }^{\text {corr }}=9.69 \times 10^{-4}$ cgsu, $\mu_{e f f}=1.53$ BM. UV-Vis (toluene): $\lambda_{\max } / \mathrm{nm}\left(\varepsilon / \mathrm{M}^{-1} \mathrm{~cm}^{-1}\right)=361(40) . \Lambda_{\mathrm{M}}$ (toluene) $=0.1$ $\mathrm{S} \cdot \mathrm{cm}^{2} \cdot \mathrm{mol}^{-1}$. Compound 6 was obtained by a procedure analogous to that described above, by allowing 2a (freshly prepared from $1.00 \mathrm{mmol}$ of $\mathrm{NbOCl}_{3}$ ) to react with $\mathrm{NaOMe}(54 \mathrm{mg}, 1.00 \mathrm{mmol})$. Complex 6 could be isolated as a sticky, strongly air sensitive light brown solid. Yield $93 \mathrm{mg}, 53 \%$. NMR analysis on an aliquot of 6 (ca. $20 \mathrm{mg}$ ) dissolved into $\mathrm{CDCl}_{3}(0.7 \mathrm{~mL})$ and then treated with a large excess of $\mathrm{H}_{2} \mathrm{O}$ pointed out the presence of $\mathrm{MeOH}$. Anal. Calcd. for $\mathrm{CH}_{3} \mathrm{ClNbO}_{2}: \mathrm{C}, 6.85 ; \mathrm{H}, 1.72 ; \mathrm{Nb}, 52.97 ; \mathrm{Cl}$, 20.21. Found: C, 6.76; H, 1.75; Nb, 52.65; Cl, 19.98. IR (solid state): $v=2920 \mathrm{w}, 2821 \mathrm{w}, 1579 \mathrm{w}$, $1450 \mathrm{w}, 1373 \mathrm{w}, 1152 \mathrm{~m}, 1083 \mathrm{~m}, 1014 \mathrm{vs}, 854 \mathrm{~m}-\mathrm{sh}, 816 \mathrm{~s}-\mathrm{sh}(\mathrm{Nb}=\mathrm{O}), 793 \mathrm{vs}, 682 \mathrm{~s} \mathrm{~cm} \mathrm{~cm}^{-1}$. Magnetic measurement: $\chi_{M}{ }^{\text {corr }}=8.67 \times 10^{-4} \mathrm{cgsu}, \mu_{\text {eff }}=1.44 \mathrm{BM}$. UV-Vis $\left(\mathrm{CH}_{2} \mathrm{Cl}_{2}\right): \lambda_{\max } / \mathrm{nm}\left(\varepsilon / \mathrm{M}^{-1} \mathrm{~cm}^{-1}\right)=362$ $\left(6 \cdot 10^{2}\right), 438(70) . \Lambda_{\mathrm{M}}($ toluene $)=0.1 \mathrm{~S} \cdot \mathrm{cm}^{2} \cdot \mathrm{mol}^{-1}$. 


\section{X-ray crystallography.}

Crystal data and collection details for $\mathbf{3} \cdot(1 / 2$ hexane) and $4 \cdot$ toluene are reported in Table 2 . The diffraction experiments were carried out on a Bruker APEX II diffractometer equipped with a CCD detector using Mo-K $\alpha$ radiation. Data were corrected for Lorentz polarization and absorption effects (empirical absorption correction SADABS). ${ }^{37}$ Structures were solved by direct methods and refined by full-matrix least-squares based on all data using $F^{2} \cdot{ }^{38}$ Hydrogen atoms were fixed at calculated positions and refined by a riding model. All non-hydrogen atoms were refined with anisotropic displacement parameters unless otherwise stated. The hexane molecule in $\mathbf{3} \cdot(1 / 2$ hexane $)$ is disordered over two equally populated symmetry related (by 2) positions. Its independent image has been refined isotropically applying restraints to the thermal parameters (SIMU line in SHELXL; s.u. 0.005) and to the C-C distances (DFIX 1.53 line in SHELXL; s.u. 0.01).

\begin{tabular}{lcc} 
Table 2. Crystal data and experimental details for $\mathbf{3} \cdot(1 / 2$ hexane) and $\mathbf{4} \cdot$ toluene. & \\
\hline & $\mathbf{3} \cdot(1 / 2$ hexane $)$ & $\mathbf{4} \cdot$ toluene \\
Formula & $\mathrm{C}_{45} \mathrm{H}_{55} \mathrm{Cl}_{2} \mathrm{~N}_{4} \mathrm{NbO}$ & $\mathrm{C}_{45} \mathrm{H}_{48} \mathrm{Br}_{2} \mathrm{~N}_{4} \mathrm{NbO}$ \\
$F w$ & 831.74 & 913.60 \\
$\mathrm{~T}, \mathrm{~K}$ & $100(2)$ & $100((2)$ \\
$\lambda, \AA$ & 0.71073 & 0.71073 \\
Crystal system & Monoclinic & Orthorhombic \\
Space group & $C 2 / c$ & $P b c a$ \\
$a, \AA$ & $30.131(6)$ & $21.228(3)$ \\
$b, \AA$ & $12.795(2)$ & $15.011(2)$ \\
$c, \AA$ & $24.138(5)$ & $26.045(4)$ \\
$\beta,^{\circ}$ & $100.206(3)$ & 90 \\
Cell Volume, $\AA^{3}$ & $9159(3)$ & $8299(2)$ \\
$Z$ & 8 & 8 \\
$D_{c}, \mathrm{~g} \mathrm{~cm}^{-3}$ & 1.206 & 1.462 \\
$\mu, \mathrm{mm}^{-1}$ & 0.415 & 2.254
\end{tabular}




\begin{tabular}{lcc}
$\mathrm{F}(000)$ & 3488 & 3720 \\
Crystal size, $\mathrm{mm}$ & $0.16 \times 0.13 \times 0.10$ & $0.18 \times 0.16 \times 0.14$ \\
$\theta$ limits, ${ }^{\circ}$ & $1.37-26.00$ & $1.56-25.03$ \\
Reflections collected & 43118 & 56936 \\
Independent reflections & $8988\left[R_{\mathrm{int}}=0.0821\right]$ & $7308\left[R_{\mathrm{int}}=0.0765\right]$ \\
Data / restraints /parameters & $8988 / 246 / 475$ & $7308 / 6 / 478$ \\
Goodness of fit on $\mathrm{F}^{2}$ & 1.033 & 1.044 \\
$R_{1}(I>2 \sigma(I))$ & 0.0742 & 0.0806 \\
$w R_{2}($ all data) & 0.2383 & 0.2651 \\
Largest diff. peak and hole, e $\AA^{-3}$ & $1.981 /-0.963$ & $2.824 /-2.819$ \\
\hline
\end{tabular}

\section{Computational studies.}

The computational geometry optimizations were carried out without symmetry constrains, using the hybrid-GGA EDF2 functional ${ }^{39}$ in combination with the $6-31 \mathrm{G}^{* *}$ basis set (ECP-based LANL2DZ basis set for elements beyond $\mathrm{Kr}){ }^{40}$ The "unrestricted" formalism was applied for compounds with unpaired electrons, and the lack of spin contamination was verified by comparing the computed $<\mathrm{S}^{2}>$ values with the theoretical ones. The stationary points were characterized by IR simulations (harmonic approximation), from which zero-point vibrational energies and thermal corrections $(\mathrm{T}=298.15 \mathrm{~K})$ were obtained. ${ }^{41}$ Further optimization of selected geometries was carried out using the range-separated DFT functional $\omega \mathrm{B} 97 \mathrm{X},{ }^{42}$ in combination with a polarized basis set composed by the $6-31 \mathrm{G}(\mathrm{d}, \mathrm{p})$ set on the light atoms and the ECP-based LANL2TZ(f) and LANL2DZ(d) sets on niobium and bromine, respectively. ${ }^{43}$ The C-PCM implicit solvation model $(\varepsilon=9.08)$ was added to $\omega$ B97X calculations. ${ }^{44}$ The software used for C-PCM/ $\omega$ B97X calculations was Gaussian ' $09,{ }^{45}$ while EDF2 calculations were performed with Spartan '08. ${ }^{46}$ 
Supporting Information. Figures S1-S5 show the DFT-calculated structures of 1b and 2a-d; tables S1S5 contain the relevant bonding parameters. Cartesian coordinates of all DFT-optimized compounds are collected in a separated .xyz file. CCDC reference numbers 1438214 (3) and 1438215 (4) contain the supplementary crystallographic data for the X-ray studies reported in this paper. These data can be obtained free of charge at www.ccdc.cam.ac.uk/conts/retrieving.html (or from the Cambridge Crystallographic Data Centre, 12, Union Road, CambridgeCB2 1EZ, UK; fax: (internat.) +44-1223/336033; e-mail: deposit@ccdc.cam.ac.uk).

\section{Acknowledgement}

We thank the University of Pisa for financial support.

\section{References and Notes}

Recent references include: (a) Lazreg, F.; Nahra, F.; Cazin, C. S. J. Coord. Chem. Rev. 2015, 293294, 48-79. (b) Nelson, D. J. Eur. J. Inorg. Chem. 2015, 2012-2027. (c) Hackenberg, F.; Tacke, M. Dalton Trans. 2014, 43, 8144-8153. (d) Broggi, J.; Jurcík, V.; Songis, O.; Poater, A.; Cavallo, L.; Slawin, A. M. Z.; Cazin, C. S. J. J. Am. Chem. Soc. 2013, 135, 4588-4591. (e) DePasquale, J.; Kumar, M.; Zeller, M.; Papish, E. T. Organometallics 2013, 32, 966-979. (f) Donnelly, K; Petronilho, A.; Albrecht, M. Chem. Commun. 2013, 49, 1145-1159. (g) Oehninger, L.; Rubbiani, R.; Ott, I. Dalton Trans. 2013, 3269-3284. (h) Diaz Velazquez, H.; Verpoort, F. Chem. Soc. Rev. 2012, 
41, 7032-7060. (i) Hindi, K. M.; Panzner, M. J.; Tessier, C. A.; Cannon, C. L.; Youngs, W. J. Chem. Rev. 2009, 109, 3859-3884.

(a) Bellemin-Laponnaz, S.; Dagorne, S. Chem. Rev. 2014, 114, 8747-8774. (b) Doddi, A.; Gemel, C.; Seidel, R. W.; Winter, M.; Fischer, R. A. Polyhedron 2013, 52, 1103-1108. (c) Dodds, C. A.; Spicer, M. D.; Tuttle, T. Organometallics 2011, 30, 6262-6269. (d) Lorber, C.; Vendier, L. Dalton Trans. 2009, 6972-6984. (e) Nikiforov, G. B.; Roesky, H. W.; Jones, P. G.; Magull, J.; Ringe, A.; Oswald, R. B. Inorg. Chem. 2008, 47, 2171-2179. (f) Shukla, P.; Johnson, J. A.; Vidovic, D.; Cowley, A. H.; Abernethy, C. D. Chem. Commun. 2004, 360-361. (g) Abernethy, C. D.; Codd, G. M.; Spicer, M. D.; Taylor, M. K. J. Am. Chem. Soc. 2003, 125, 1128-1129. (h) Herrmann, W. A.; Lobmaier, G. M.; Elison, M. J. Organomet. Chem. 1996, 520, 231-234.

Bortoluzzi, M.; Ferretti, E.; Marchetti, F.; Pampaloni, G.; Zacchini, S. Chem. Commun. 2014, 50, $4472-4474$.

(a) Pugh, D.; Wright, J. A.; Freeman, S.; Danopoulos, A. A. Dalton Trans. 2006, 775-782. (b) Herrmann, W. A.; Öfele, K.; Elison, M.; Kühn, F. E.; Roesky, P. W. J. Organomet. Chem. 1994, 480, C7-C9.

(a) Coman, S. M.; Verziu, M.; Tirsoaga, A.; Jurca, B.; Teodorescu, C.; Kuncser, V.; Parvulescu, V. I.; Scholz, G.; Kemnitz, E. ACS Catal. 2015, 5, 3013-3026. (b) Satoh, Y.; Obora, Y. Eur. J. Org. Chem. 2015, 5041-5054. (c) Wilhelm, M. E.; Anthofer, M. H.; Reich, R. M.; D'Elia, V.; Basset, J.M.; Herrmann, W. A.; Cokoja, M.; Kühn, F. E. Catal. Sci. Technol. 2014, 4, 1638-1643. (d) Monassier, A.; D'Elia, V.; Cokoja, M.; Dong, H.; Pelletier, J. D. A.; Basset, J.-M.; Kühn, F. E. Chem CatChem 2013, 5, 1321-1324. (e) Redshaw, C.; Walton, M.; Clowes, L.; Hughes, D. L.; Fuller, A.-M.; Chao, Y.; Walton, A.; Sumerin, V.; Elo, P.; Soshnikov, I.; Zhao, W.; Sun, W.-H. Chem. Eur. 
J. 2013, 19, 8884-8899. (f) Marchetti, F.; Pampaloni, G. Chem. Commun. 2012, 48, 635-653, and references therein. (g) Marchetti, F.; Pinzino, C.; Zacchini, S.; Pampaloni, G. Angew. Chem. Int. Ed. 2010, 49, 5268-5272. (h) Fuchibe, K.; Kaneko, T.; Mori, K.; Akiyama, T. Angew. Chem. Int. Ed. 2009, 48, 8070-8073.

(a) Pedersen, S. F.; Hartung J. B. Jr.; Roskamp, E. J.; Dragovich, P. S. Inorg. Synth. 1992, 29,119123. (b) Hartung, J. B., Jr.; Pedersen, S. F. Organometallics 1990, 9, 1414-1417. (c) Roskamp, E. J.; Pedersen, S. F. J. Am. Chem. Soc. 1987, 109, 6551-6553. (d) Chassaing, J.; Bizot, D. J. Fluorine Chem. 1980, 16, 451-459.

7 See for instance: (a) Satoh, Y.; Obora, Y. Org. Lett. 2011, 13, 2568-2571. (b) Obora, Y.; Kimura, M.; Tokunaga, M.; Tsuji, Y. Chem. Commun. 2005, 901-902.

(a) Hartwig, S.; Hillebrecht, Z. Anorg. Allg. Chem. 2008, 634, 115-120. (b) H. Köhler, J.; Simon, A.; van Wüllen, L.; Cordier, S.; Roisnel, T.; Poulain, M.; Somer, M. Z. Anorg. Allg. Chem. 2002, 628, 2683-2690. (c) Gibson, V. C.; Kee, T. P.; Shaw, A. Polyhedron 1990, 9, 2293-2298. Levason, W.; Reid, G.; Trayer, J.; Zhang, W. Dalton Trans. 2014, 43, 3649-3659, and references therein.

(a) Tran, T. T.; Gooch, M.; Lorenz, B.; Litvinchuk, A. P.; Sorolla, M. G. II; Brgoch, J.; Chu, P. C. W.; Guloy, A. M. J. Am. Chem. Soc. 2015, 137, 636-639. (b) Cordier, S.; Gulo, F.; Roisnel, T.; Gautier, R.; le Guennic, B.; Halet, J. F.; Perrin, C. Inorg. Chem. 2003, 42, 8320-8327. (c) Whangbo, M. H. Inorg. Chem. 1982, 21, 1721-1723.

11 (a) Beck, J.; Kusterer, C. Z. Anorg. Allg. Chem. 2006, 632, 2193-2194. (b) Fairbrother, F. The Halides of Niobium and Tantalum, in Halogen Chemistry, Ed. Gutmann, V., 1967, Volume 3, pp. 
123-178, Academic Press, London and New York. (c) Schäfer, H.; Sibbing, E.; Gerken, R. Z. Anorg. Allg. Chem. 1961, 307, 163-173.

(a) Cotton, F. A.; Lu, J. Inorg. Chem. 1995, 34, 2639-2644. (b) Buslaev, Yu. A.; Glushkova, M. A.;

Ovchinnikova, N. A. Russian J. Coord. Chem. 1975, 1, 319-322.

Marchetti, F.; Pampaloni, G.; Zacchini, S. Chem. Commun. 2008, 3651-3653.

(a) Bondi, R.; Marchetti, F.; Pampaloni, G.; Zacchini, S. Polyhedron 2015, 100, 192-198. (b) P. J. Alonso, I. Ara, A. B. Arauzo, M. A. Garcia-Monforte, B. Menjon and C. Rillo, Angew. Chem. Int. Ed. 2010, 49, 6143 -6146. (c) M. P. Donzello, C. Ercolani, A. Chiesi-Villa and C. Rizzoli, Inorg. Chem. 1998, 37, 1347-1351. (d) Bochmann, M.; Wilkinson, G.; Young, G. B.; Hursthouse, M. B.; Abdul Malik, K. M.; J. Chem. Soc., Dalton Trans. 1980, 901-910. (e) Manzer, L. E. Inorg. Chem. 1977, 16, 525-528. (f) Deutscher, R. L.; Kepert, D. L. Inorg. Chim. Acta 1970, 4, 645-650. (g) C. Djordjevic and V. Katovic, Chem. Commun. 1966, 224-225.

16 (a) Wells, A. F. Structural Inorganic Chemistry, 5th Edition, Clarendon Press, Oxford, 1993. (b) Zalkin, A., Sands, D. E. Acta Crystallogr. 1958, 11, 615-619.

Sands, D. E.; Zalkin, A. Acta Cryst. 1959, 12, 723-726.

Schäfer, H.; v. Schnering H.-G.; Tillack, J.; Kuhnen, T.; Wöhrle, H.; Baumann, H. Z. Anorg. Allg. Chem. 1967, 353, 281-310.

(a) Dastych, D.; Rotter, P.; Demo, G.; Dastychova, L. Acta Cryst. 2011, E67, m1398. (b) Priebsch, W.; Weidemann, C.; Rehder, D.; Kopf, J. Z. Naturforsch. B 1986, 41, 834-838.

Computed $\Delta \mathrm{G}$ values for the dimerization reactions $2 \mathrm{Nb}(\mathrm{O}) \mathrm{X}_{2}(\mathrm{dme}) \rightarrow\left[\mathrm{Nb}(\mathrm{O}) \mathrm{X}_{2}(\mathrm{dme})\right]_{2}$ resulted to be $-17.7 \mathrm{kcal} \mathrm{mol}^{-1}(\mathrm{X}=\mathrm{Cl})$ and $-15.9 \mathrm{kcal} \mathrm{mol}^{-1}(\mathrm{X}=\mathrm{Br})$, respectively. 
(a) Bortoluzzi, M.; Ghini, F.; Hayatifar, M.; Marchetti, F.; Pampaloni, G.; Zacchini, S. Eur. J. Inorg. Chem. 2013, 3112-3118. (b) Hubert-Pfalzgraf, L. G.; Pinkerton, A. A. Inorg. Chem. 1977, $16,1895-1897$.

Kilgore, U. J.; Tomaszewski, J.; Fan, H.; Huffman, J. C.; Mindiola, D. J. Organometallics 2007, 26, $6132-6138$.

Schweiger, S. W.; Salberg, M. M.; Pulvirenti, A. L.; Freeman, E. E.; Fanwick, P. E.; Rothwell, I. P. J. Chem. Soc., Dalton Trans. 2001, 2020-2031.

Bondi, A. J. Phys. Chem. 1964, 68, 441-451.

The hydrolysis of the reaction mixtures facilitated the release of the organic material from the paramagnetic metal species, thus allowing the NMR identification of the former. This strategy has been extensively employed for the study of the coordination chemistry of niobium and tantalum pentahalides [5f].

Baird, M. C. Progr. Inorg. Chem. 1968, 9, 1-159.

Kharitonov, Y. Y.; Lipatova, N. P. Izvestiya Akademii Nauk SSSR, Neorganicheskie Materialy 1967, 3, 405-407.

28 Calderazzo, F.; Pallavicini, P.; Pampaloni, G.; Zanazzi, P. F. J. Chem. Soc., Dalton Trans. 1990, 2743-2746.

(a) Arduengo, A. J. III; Krafczyk, R.; Schmutzler, R.; Craig, H. A.; Goerlich, J. R.; Marshall, W. J.; Unverzagt, M. Tetrahedron 1999, 55, 14523-14534. (b) Hintermann, L. Beilst. J. Org. Chem. 2007, 3, doi:10.1186/1860-5397-3-22.

30 a) Jutand, A. Eur. J. Inorg. Chem., 2003, 2017-2040. b) Geary, W. J. Coord. Chem. Rev., 1971, 7, $81-122$

31 Ambrosetti, R.; Ricci, D. Rev. Sci. Instrum. 1991, 62, 2281-2287. 
32 Pinzino, C.; Forte, C. EPR-ENDOR, ICQEM-CNR Rome, Italy 1992.

33 Duling, D. R. J. Magn. Reson. B 1994, 104, 105-110.

34 König, E. Magnetische Eigenschaften der Koordinations- und Metallorganischen Verbindungen der Übergangselemente in Landolt-Börnstein, Zahlenwerte und Funktionen aus Naturwissenschaften und Technik, 6th Ed., Springer-Verlag, Berlin, Göttingen, Heidelberg, 1966, 2, 16.

Willker, W.; Leibfritz, D.; Kerssebaum, R.; Bermel, W. Magn. Reson. Chem. 1993, 31, 287-292.

Skoog, D. A.; West, D. M.; Holler, F. J. Fundamentals of Analytical Chemistry, 7th Edition, Thomson Learning, Inc, USA, 1996.

37 Sheldrick, G. M. SADABS, Program for empirical absorption correction, University of Göttingen, Germany, 1996.

38 Sheldrick, G. M. SHELX97, Program for crystal structure determination, University of Göttingen, Germany, 1997. Lin, C. Y.; George, M. W.; Gill, P. M. W. Aust. J. Chem. 2004, 57, 365-370.

(a) Dolg, M. Modern Methods and Algorithms of Quantum Chemistry, J. Grotendorst Ed., John Neumann Institute for Computing, NIC series, Jülich, 2000, 1, 479. (b) Hay, P. J.; Wadt, W. R. J. Chem. Phys. 1985, 82, 270-283. (c) Hay, P. J.; Wadt, W. R. J. Chem. Phys. 1985, 82, 299-310. (d) Henre, W. J.; Ditchfield, R.; Pople, J. A. J. Chem. Phys. 1972, 56, 2257-2261.

(a) Minenkov, Yu.; Singstad, Å; Occhipinti G.; Jensen V. R. Dalton Trans. 2012, 41, 5526-5541.

(b) Chai, J.-D.; Head-Gordon, M. Phys. Chem. Chem. Phys. 2008, 10, 6615-6620. (c) Gerber I. C.; Ángyán, J. G. Chem. Phys. Lett. 2005, 415, 100-105. 
43 (a) Roy, L. E.; Hay, P. J.; Martin, R. L. J. Chem. Theory Comput. 2008, 4, 1029-1031. (b) Francl, M. M.; Pietro, W. J.; Hehre, W. J.; Binkley, J. S.; DeFrees, D. J.; Pople, J. A.; Gordon, M. S. J. Chem. Phys. 1982, 77, 3654-3665.

(a) Cossi, M.; Rega, N.; Scalmani, G.; Barone, V. J. Comput. Chem. 2003, 24, 669-681. (b) Barone, V.; Cossi, M. J. Phys. Chem. A 1998, 102, 1995-2001.

45 Gaussian 09, Revision C.01, Frisch, M. J. et al., Gaussian, Inc., Wallingford CT, 2010. and semi-empirical models, the calculation methods used in Spartan have been documented in: Shao, Y. et al. Phys. Chem. Chem. Phys. 2006, 8, 3172-3191. 


\section{Table of Contents Synopsis and graphic}

Coordination compounds of $\mathrm{Nb}(\mathrm{IV})$ oxide dihalides were synthesized and characterized, including the crystallographic characterization of rare $\mathrm{Nb}-\mathrm{NHC}$ complexes.

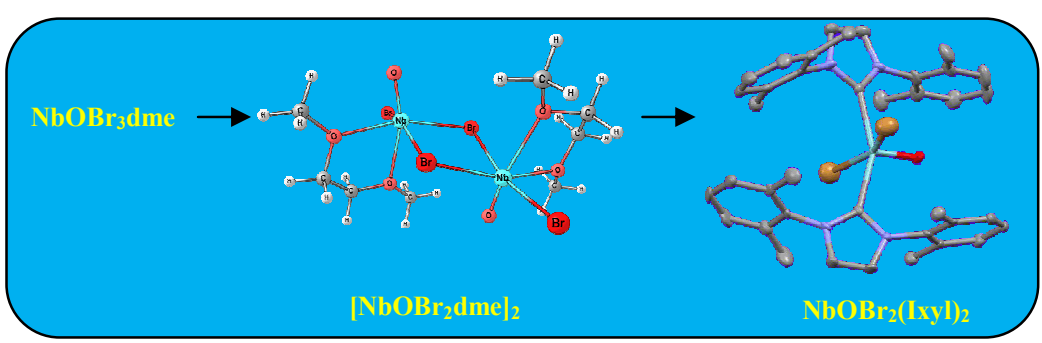

